\title{
Investigation of the effective peak supersaturation for liquid-phase clouds at the high-alpine site Jungfraujoch, Switzerland (3580 m a.s.l.)
}

\author{
E. Hammer ${ }^{1}$, N. Bukowiecki ${ }^{1}$, M. Gysel ${ }^{1}$, Z. Jurányi ${ }^{1, *}$, C. R. Hoyle ${ }^{1,3}$, R. Vogt $^{2}$, U. Baltensperger ${ }^{1}$, and \\ E. Weingartner ${ }^{1, *}$ \\ ${ }^{1}$ Laboratory of Atmospheric Chemistry, Paul Scherrer Institute, Switzerland \\ ${ }^{2}$ Meteorology, Climatology and Remote Sensing, University of Basel, Switzerland \\ ${ }^{3}$ Swiss Federal Institute for Forest Snow and Landscape Research (WSL)-Institute for Snow and Avalanche Research (SLF), \\ Davos, Switzerland \\ *now at: Institute for Aerosol and Sensor Technology, University of Applied Sciences and Arts Northwestern Switzerland, \\ Switzerland
}

Correspondence to: E. Weingartner (ernest.weingartner@fhnw.ch)

Received: 17 July 2013 - Published in Atmos. Chem. Phys. Discuss.: 6 August 2013

Revised: 26 November 2013 - Accepted: 15 December 2013 - Published: 29 January 2014

\begin{abstract}
Aerosols influence the Earth's radiation budget directly through absorption and scattering of solar radiation in the atmosphere but also indirectly by modifying the properties of clouds. However, climate models still suffer from large uncertainties as a result of insufficient understanding of aerosol-cloud interactions. At the high altitude research station Jungfraujoch (JFJ; $3580 \mathrm{~m}$ a.s.l., Switzerland) cloud condensation nuclei $(\mathrm{CCN})$ number concentrations at eight different supersaturations (SS) from $0.24 \%$ to $1.18 \%$ were measured using a CCN counter during Summer 2011. Simultaneously, in-situ aerosol activation properties of the prevailing ambient clouds were investigated by measuring the total and interstitial (non-activated) dry particle number size distributions behind two different inlet systems. Combining all experimental data, a new method was developed to retrieve the so-called effective peak supersaturation $\mathrm{SS}_{\text {peak }}$, as a measure of the SS at which ambient clouds are formed. A 17month CCN climatology was then used to retrieve the $\mathrm{SS}_{\text {peak }}$ values also for four earlier summer campaigns (2000, 2002, 2004 and 2010) where no direct CCN data were available. The $\mathrm{SS}_{\text {peak }}$ values varied between $0.01 \%$ and $2.0 \%$ during all campaigns. An overall median $\mathrm{SS}_{\text {peak }}$ of $0.35 \%$ and dry activation diameter of $87 \mathrm{~nm}$ was observed. It was found that the difference in topography between northwest and southeast plays an important role for the effective peak supersaturation in clouds formed in the vicinity of the JFJ, while dif-
\end{abstract}

ferences in the number concentration of potential CCN only play a minor role. Results show that air masses coming from the southeast (with the slowly rising terrain of the Aletsch Glacier) generally experience lower $\mathrm{SS}_{\text {peak }}$ values than air masses coming from the northwest (steep slope). The observed overall median values were $0.41 \%$ and $0.22 \%$ for northwest and southeast wind conditions, respectively, corresponding to literature values for cumulus clouds and shallowlayer clouds. These cloud types are consistent with weather observations routinely performed at the JFJ.

\section{Introduction}

Cloud droplets may form when aerosol particles are exposed to air that is supersaturated with respect to water vapour. Those particles that are activated and become cloud droplets are referred to as cloud condensation nuclei (CCN). Changes in the number of aerosol particles, their dry size or chemical composition may alter the $\mathrm{CCN}$ number concentration. A change in the $\mathrm{CCN}$ number concentration (e.g. due to anthropogenic influences) modifies the microphysical and radiative properties of clouds and therefore affects the climate as well. When the CCN number concentration is higher, more but smaller droplets are formed in warm clouds, than 
when the CCN number concentration is lower (Twomey, 1977). This increases the amount of solar radiation reflected by the clouds, since distributing the available liquid water among more droplets increases the total cloud droplet surface area which results in an increased cloud albedo. In addition, smaller droplets have a lower fall velocity, which reduces the auto-conversion rate, suppressing the formation of precipitation and increasing the lifetime of clouds (Albrecht, 1989). Changes of these indirect aerosol effects on climate, caused by anthropogenic activities, result, on a global scale, in a negative radiative forcing (IPCC, 2007). However, the scientific understanding of these effects is low and the resulting uncertainties of the radiative forcing are large (IPCC, 2007).

Aerosol indirect effects depend on the number concentration of $\mathrm{CCN}$. The number concentration of $\mathrm{CCN}$ is determined by the aerosol number size distribution and hygroscopic properties as well as the present supersaturation. Thus, to address the aerosol-cloud interaction processes in detail, properties such as size, composition and mixing state of the individual particles need to be known. However, present climate models are not capable of representing these aerosol properties in the required detail. Hence, compromises and assumptions that accurately address the most important aerosol effects within the constraints of practical application are required (Ghan et al., 1998).

One of the properties that can be used to characterise the $\mathrm{CCN}$ activity of an aerosol is the critical supersaturation, i.e. the lowest supersaturation at which the particle is activated to a cloud droplet. The critical supersaturation depends on the particle's size and chemical composition and is described by Köhler theory (Kohler, 1936). Many studies have used CCN counters to investigate the critical supersaturation of ambient aerosol particles as well as the CCN number concentration under controlled supersaturation conditions (e.g. Fors et al., 2011; Padro et al., 2012; Deng et al., 2013; Sihto et al., 2011).

Whether a particle acts as a CCN in the atmosphere depends, aside from the particle's chemical and physical properties, on the supersaturation of the water vapour. As a saturated air parcel continues to cool, it becomes supersaturated and those particles with a critical supersaturation at or below the supersaturation in the air parcel will become activated to form cloud droplets. The supersaturation in an air parcel reaches its peak value when the sink term (condensation) becomes equal to the source term (cooling), after which point the relative humidity decays towards $100 \%$ as the growing droplets continue to deplete the gas phase water. The supersaturation is typically inhomogeneous in space and time. The highest supersaturation that a particle experiences for a sufficiently long time to grow to a stable cloud droplet is defined here as the effective peak supersaturation $\left(\mathrm{SS}_{\text {peak }}\right)$. In some literature it has also been referred to as "maximal supersaturation"; "effective" is used here rather than "maximal" because very short supersaturation spikes that do not lead to droplet activation are irrelevant in this context. $\mathrm{SS}_{\text {peak }}$ is a key parameter for aerosol-to-cloud droplet activation and thus is an important quantity for cloud parameterizations in climate models (e.g. Zhao et al., 2012).

As it is practically impossible to observe exactly where and when the droplets in most kinds of clouds formed, $\mathrm{SS}_{\text {peak }}$ cannot be directly measured, it can only be retrieved indirectly from other measurements. Only few studies determined $\mathrm{SS}_{\text {peak }}$ in ambient clouds experimentally using dry particle size distributions and their hygroscopic properties (e.g. Anttila et al., 2009; Asmi et al., 2012, Ditas et al., 2012).

In the present work, we quantify the $\mathrm{SS}_{\text {peak }}$ experienced by aerosols in clouds observed at the Jungfraujoch. A methodology for retrieving this parameter is presented, and the effective peak supersaturation is retrieved from datasets obtained in a dedicated measurement campaign (CLACE2011; described in Sect. 2) as well as earlier campaigns when the activation of aerosol particles to cloud droplets in ambient warm clouds (i.e. liquid-phase clouds) was measured. Thereafter, the factors influencing the effective peak supersaturation, such as topography, meteorological parameters, and aerosol properties, are discussed in detail.

\section{Experimental}

\subsection{Measurement site and CLACE campaigns}

All measurements presented in this study were performed at the high-alpine research station Jungfraujoch (hereafter abbreviated JFJ). The station is located at an altitude of $3580 \mathrm{~m}$ a.s.l. in the Bernese Alps and it is easily accessible by train throughout the year. This special location offers the opportunity to monitor aerosol properties within the lower free troposphere (e.g. Cozic et al., 2008; Weingartner et al., 1999). Aerosol measurements have been performed at the JFJ for more than $20 \mathrm{yr}$ (e.g. Collaud Coen et al., 2013; Baltensperger et al., 1997). Since 1995 the station has been part of the Global Atmosphere Watch (GAW) program of the World Meteorological Organization. Because of the high altitude of the research station, it is located within clouds for about $40 \%$ of the time, and the cloud base regularly rises and lowers vertically past the station, making it a convenient location for performing $\mathrm{CCN}$ measurements within clouds (Baltensperger et al., 1998). Local particle emissions are very low, however, in recent years, the outdoor tourism activities near the station have increased. This results in more frequent local pollution due to construction activities and snow groomer emissions, and requires care when analysing the data.

The Jungfraujoch research station is located on a crest between the summits of two mountains, the Mönch (4099 ma.s.1.) and the Jungfrau (4158 ma.s.1.) to the SW (southwest) and NE (northeast), respectively (Fig. 1c and d). Due to this local topography around the JFJ, the wind is predominantly either from the NW or the SE (Fig. 1b). The topography to the NW of the JFJ differs from that on 

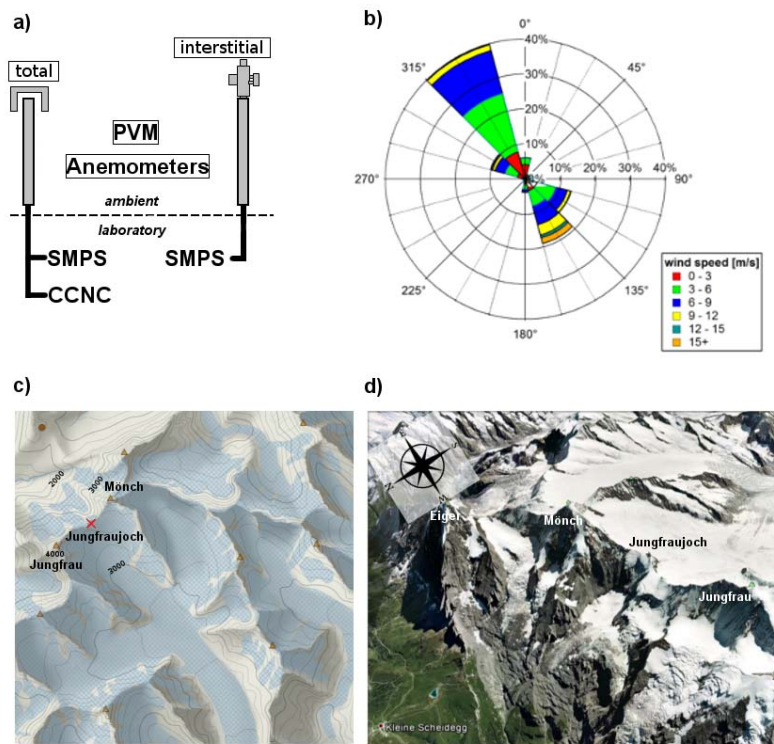

d)

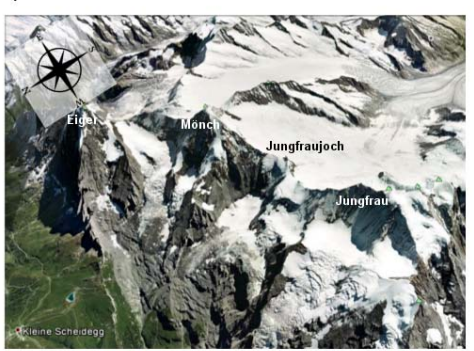

Fig. 1. In (a) the measurement setup is shown in a sketch with the two different inlet systems. An overview of the major wind directions during CLACE2011 (data source: MeteoSwiss) around the JFJ is shown in (b) and the corresponding altitude profile in (c). In (d) a satellite picture is shown looking towards Southeast ( ${ }^{\circledR}$ GoogleEarth, 9 January 2010, Flotron/Perrinjaquet).

the southeastern side (see Fig. 1c and d). To the southeast, the Great Aletsch glacier declines gradually from the JFJ $(1500 \mathrm{~m}$ of altitude decrease over $18 \mathrm{~km})$ while the northwestern side drops steeply, descending $1500 \mathrm{~m}$ over a horizontal distance of $4800 \mathrm{~m}$ (Ketterer et al., 2014).

Since the year 2000, several intensive measurement campaigns for the investigation of aerosol-cloud interactions have taken place at the JFJ site. These campaigns are called CLACE (Cloud and Aerosol Characterisation Experiment). Several of them investigated warm clouds during Summer (25 July-10 August 2000, CLACE2000: Henning et al., 2002; 4-20 July 2002, CLACE2002; 16 July-30 September 2004, CLACE2004: Cozic et al., 2007; 19 June-7 August 2010, CLACE2010: Spiegel et al., 2012; 29 June-24 August 2011, CLACE2011: this study). The main focus of the campaigns was to investigate the physical, chemical and optical properties of aerosols as well as the interaction of the aerosol particles with clouds, for a better quantification of the aerosol direct and indirect effects. During these campaigns, parameters such as cloud droplet size distributions, cloud liquid water content, interstitial aerosol size distribution were measured in addition to the continuous GAW aerosol measurements (number concentration, number size distribution, light scattering coefficient, light absorption coefficient, equivalent black carbon concentration, and aerosol chemical composition).

\subsection{Instrumentation}

The following description refers to the experimental setup for the CLACE2011 campaign. The datasets of the other CLACE campaigns were acquired with the same or equivalent instruments. For the sampling of the aerosols and hydrometeors, an interstitial and a total inlet were installed on the roof of the laboratory. The interstitial inlet consists of a cyclone ( $\mathrm{PM}_{2.5}$, Very Sharp Cut Cyclone, BGI, USA) which was used to remove droplets larger than $2 \mu \mathrm{m}$ in aerodynamic diameter. It was operated at ambient temperatures (typically at -12 to $11^{\circ} \mathrm{C}$; Henning et al., 2002) and at a flow rate of $20 \mathrm{~L} \mathrm{~min}^{-1}$. Thus, exclusively non-activated particles (i.e. particles that did not act as $\mathrm{CCN}$ ) passed into this inlet. In the laboratory, the aerosol was dried to $\mathrm{RH}<10 \%$ as it was heated to room temperature (typically 20 to $30^{\circ} \mathrm{C}$ ). The total inlet collected all particles (including hydrometeors) smaller than approximately $40 \mu \mathrm{m}$, at wind speeds up to $20 \mathrm{~ms}^{-1}$ (Weingartner et al., 1999). The water associated with the hydrometeors and aerosol particles was evaporated by heating up the top part of this inlet to approximately $20^{\circ} \mathrm{C}$, and subsequently all dried aerosol particles (non-activated aerosols and the residuals of the cloud droplets and ice crystals) reached the instruments in the laboratory. Since the difference between the number concentrations measured behind the total and the interstitial inlets measured behind the total minus the interstitial number concentration corresponds to the number of cloud residuals, i.e. the number of particles that have been activated to cloud droplets, can be compared to the number of cloud droplets directly measured in the ambient air (see Sect. 3.3). The study of Henning et al. (2002) shows a good correlation between the cloud residual concentrations and the integrated cloud droplet number concentrations measured with a forward scattering spectrometer probe (FSSP-100) during CLACE2000. During CLACE2010 a Fog Monitor (FM-100) was employed to measure the cloud droplet size distribution. Unfortunately, it was very difficult measuring the cloud droplets with this instrument at the JFJ because high wind velocities led to strong measurement artifacts, as described by Spiegel et al. (2012). However, the study showed that a good agreement between integrated cloud droplet number concentration and cloud residuals (total-interstitial) was found after accounting for these droplet losses of the FM-100, by applying experimentally and theoretically derived formulas for the different loss mechanisms based on Spiegel et al. (2012).

Downstream of the inlets, three instruments were used in this study to measure the dry aerosol properties (see Table 1). Two scanning mobility particle sizers (SMPS) were used to measure the total and interstitial aerosol number size distribution, respectively. The instruments were run as described in Jurányi et al. (2011): the SMPS system behind the total inlet consisted of a differential mobility analyser (DMA; TSI 3071) and a condensation particle counter (CPC; TSI CPC 3775). The other system behind the interstitial inlet 
Table 1. Instrumentation for CLACE2011.

\begin{tabular}{|c|c|c|c|c|}
\hline Measured parameter(s) & Instrument & Accuracy & $\begin{array}{l}\text { Measurement } \\
\text { range }\end{array}$ & $\begin{array}{l}\text { Time } \\
\text { resolution }\end{array}$ \\
\hline $\begin{array}{l}\text { Aerosol number size } \\
\text { distribution }\end{array}$ & $\begin{array}{l}\text { Scanning mobility } \\
\text { particle sizer (SMPS) }\end{array}$ & $\begin{array}{l}\text { Number concentration: } \\
\pm 20 \%(20>D<50 \mathrm{~nm}) \\
\pm 10 \%(D>50 \mathrm{~nm})\end{array}$ & $D=16 \mathrm{~nm}-600 \mathrm{~nm}$ & $6 \mathrm{~min}$ \\
\hline $\begin{array}{l}\text { Cloud condensation } \\
\text { nuclei }(\mathrm{CCN}) \text { number } \\
\text { concentration }\end{array}$ & $\begin{array}{c}\text { Continuous flow } \\
\text { streamwise thermal } \\
\text { gradient CCN chamber }\end{array}$ & $\begin{array}{c}\text { SS: } \pm 10 \% \\
\text { Number conc.: } \pm 10 \% \\
\text { (Rose et al., 2008) }\end{array}$ & $\mathrm{SS}=0.12-1.18 \%$ & $\begin{array}{c}1 \mathrm{~s} \\
(1 \mathrm{SS} \text { cycle lasts } 1 \mathrm{~h})\end{array}$ \\
\hline $\begin{array}{l}\text { Liquid water content } \\
\text { (LWC) }\end{array}$ & $\begin{array}{c}\text { Particle volume } \\
\text { monitor (PVM-100) }\end{array}$ & $\begin{array}{c} \pm 15 \% \\
\text { (Allan et al., 2008) }\end{array}$ & $D=3-50 \mu \mathrm{m}$ & $10 \mathrm{~s}$ \\
\hline Temperature & $\begin{array}{c}\text { Thermo-hygrometer } \\
\text { Thygan VTP-37 }\end{array}$ & $\begin{array}{c} \pm 0.15^{\circ} \mathrm{K} \\
\text { (Meteolabor AG data sheet) }\end{array}$ & $T=-50-\sim 20^{\circ} \mathrm{C}$ & $10 \mathrm{~min}$ \\
\hline $\begin{array}{l}\text { horizontal wind speed } \\
\text { and direction }\end{array}$ & $\begin{array}{l}\text { Rosemount } \\
\text { anemometer }\end{array}$ & $\begin{array}{l}< \pm 1 \mathrm{~ms}^{-1} \\
\text { (Makkonen et al., 2001) }\end{array}$ & $\begin{array}{l}\text { direction: } 0-360^{\circ} \\
\text { speed: N/A }\end{array}$ & $10 \mathrm{~min}$ \\
\hline $\begin{array}{l}\text { 3-dimensional } \\
\text { wind field }\end{array}$ & $\begin{array}{l}\text { Sonic anemometer } \\
\text { Metek USA-1 }\end{array}$ & $\begin{array}{c} \pm 0.1 \mathrm{~ms}^{-1} \\
\text { (Metek USA-1 Manual) }\end{array}$ & $\pm 50 \mathrm{~ms}^{-1}$ & $20 \mathrm{~Hz}$ \\
\hline
\end{tabular}

consisted of the same DMA type and a different CPC (TSI CPC 3022a). Both DMAs were operated with a sample air flow rate of $0.3 \mathrm{~L} \mathrm{~min}^{-1}$ and a closed-loop excess and sheath air setup with a flow rate of $3 \mathrm{Lmin}^{-1}$. Each of the SMPS instruments covered the mobility diameter range from 16 to $600 \mathrm{~nm}$. The scan time to measure one size distribution was $6 \mathrm{~min}$. Various measurements at the JFJ have shown that only an insignificant number of dry particles in the size range of $600 \mathrm{~nm}$ to $2 \mu \mathrm{m}$ is present (Jurányi et al., 2010; Nyeki et al., 1998; Kammermann et al., 2010). During cloud-free periods, the two SMPS systems should, in theory, measure identical dry aerosol number size distributions. However, the measured number size distributions showed averaged differences of $10 \%$ for particles between $20 \mathrm{~nm}$ and $600 \mathrm{~nm}$. This is within the typical systematic uncertainty for this type of measurements (Wiedensohler et al., 2012). To eliminate the small differences between the two units in the calculation of the activated fraction (Sect. 3.2), the interstitial number size distributions (campaign specific instrument) were corrected towards the total number size distributions (part of the JFJ long-term measurement programme). A size and time dependent correction factor was determined by comparing the total and interstitial number size distributions during all cloud-free periods. This correction factor was then applied to the interstitial aerosol size distribution during the cloud periods by interpolating the retrieved correction factors of the start and end of the cloud periods (Verheggen et al., 2007).

A cloud condensation nuclei counter (CCNC; DMT CCNC-100, described by Roberts and Nenes, 2005) measured the polydisperse $\mathrm{CCN}$ number concentration at eight defined supersaturations (SS) behind the total inlet. The SS in the CCNC is determined by the applied temperature gradient in the activation column which has a wetted inner wall.
One measurement cycle was performed each hour, in which eight different temperature gradients in the column were set for $6 \mathrm{~min}$. The applied temperature gradients resulted in supersaturations ranging from $0.12 \%$ to $1.18 \%$. The supersaturation in the CCNC was calibrated using monodisperse ammonium sulfate particles (nebulized from a solution, dried by a diffusion drier and size selected by a DMA). Particles having a lower critical SS than the SS set in the CCNC will activate into cloud droplets and grow into micrometer sizes. An optical particle counter was used to count and measure the size of the activated droplets.

In this study it was important to know if clouds were present and what their liquid water content (LWC; condensed liquid water mass per unit volume of ambient air) was. Cloud presence and liquid water content (LWC) were measured with a PVM-100 (Gerber, 1991) which employs a measurement principle that is based on forward light scattering by the cloud droplets. The PVM-100 was regularly calibrated during the several campaigns using (1) a calibration plate that scatters the light corresponding to a certain LWC value and (2) clear sky conditions to perform a zero calibration.

An ultrasonic anemometer (Metek USA-1) was used to measure the 3-dimensional wind speed vector at the Jungfraujoch with a time resolution of $20 \mathrm{~Hz}$. The wind vector has the components $u_{\mathrm{JFJ}}, v_{\mathrm{JFJ}}$ and $w_{\mathrm{JFJ}}$, where $w_{\mathrm{JFJ}}$ is the vertical component and $v_{\mathrm{h}, \mathrm{JFJ}}=\sqrt{u_{\mathrm{JFJ}}^{2}+v_{\mathrm{JFJ}}^{2}}$ is the horizontal wind speed. The ultrasonic anemometer was installed on a $3 \mathrm{~m}$ pole pointing away from the JFJ building to reduce the influence of the building on the measured wind fields, although this influence could not be totally eliminated; especially during NW wind conditions. Therefore, the horizontal wind speed and wind direction data of the ultrasonic 
anemometer were not further used in this study. Nevertheless, the standard deviation of the vertical wind speed $\left(\sigma_{\mathrm{w}, \mathrm{JFJ}}\right)$ measured by the ultrasonic anemometer is still expected to provide information on the turbulence of the air mass.

A largely undisturbed measurement of the horizontal wind speed and wind direction at the JFJ was obtained with the Rosemount pitot tube anemometer that is mounted at the top of a $10 \mathrm{~m}$ mast located at around $75 \mathrm{~m}$ away from the ultrasonic anemometer (see Fig. 1 in Spiegel et al., 2012) as part of the SwissMetNet network of MeteoSwiss.

\section{Methods}

\subsection{Determination of cloud periods}

The LWC within a cloud is a highly fluctuating quantity, due to the cloud's spatial inhomogeneity, evaporation/condensation and due to wind fluctuations within clouds (Seinfeld and Pandis, 2006). In order to exclude measurements within cloud edges or within parts of the clouds that were influenced by entrainment of dry air, the observational dataset was filtered. To define periods when a non-patchy and sufficiently homogenous cloud was present during one number size distribution measurement $(6 \mathrm{~min})$, an adequate cloud criterion was defined for CLACE2011. For the previous CLACE campaigns we used the criterion of Henning et al. (2002) and Cozic et al. (2007) which classifies the conditions as cloudy if the LWC is higher than $20 \mathrm{mg} \mathrm{m}^{-3}$ for more than $85 \%$ of an hour. During those studies only one SMPS system was operated and switched after each SMPS scan between the interstitial and total inlet resulting in a time resolution of $12 \mathrm{~min}$. In CLACE2011, two individual SMPS systems were measuring simultaneously downstream of these inlets and thus twice the temporal resolution could be achieved. Therefore, we were able to use a less strict criterion: We defined an adequate cloud to be present when the 30th-percentile of the $10 \mathrm{~s} \mathrm{LWC}$ values distribution during 6 min (one SMPS scan) was higher than $5 \mathrm{mg} \mathrm{m}^{-3}$. Any events with an activation plateau significantly below unity were filtered in order to remove mixed-phase clouds and clouds with substantial entrainment.

\section{$3.2 \kappa$-Köhler theory}

The equilibrium saturation vapour pressure $\left(S_{\text {eq }}\right)$ over a solution droplet is described by the Köhler theory (Kohler, 1936) considering the Raoult (solute) and Kelvin effects. Petters and Kreidenweis (2007) introduced a simple parameterization for the solute term in the Köhler equation. With this, the semi-empirical " $\kappa$-Köhler equation" is obtained (here expressed for the equilibrium supersaturation $\mathrm{SS}_{\mathrm{eq}}$, which is defined as $\left.\mathrm{SS}_{\mathrm{eq}}=\mathrm{S}_{\mathrm{eq}}-1\right)$ :
$\mathrm{SS}_{\mathrm{eq}}\left(D_{\mathrm{dry}}, \kappa\right)=\frac{D^{3}-D_{\mathrm{dry}}^{3}}{D^{3}-D_{\text {dry }}^{3}(1-\kappa)} \exp \left(\frac{4 \cdot \sigma_{\mathrm{s} / \mathrm{a}} M_{\mathrm{w}}}{R T \rho_{\mathrm{w}} D}\right)-1$

where $D$ is the diameter of the droplet, $D_{\text {dry }}$ is the dry particle diameter, $\sigma_{\mathrm{s} / \mathrm{a}}$ is the surface tension of solution/air interface (in our calculations the surface tension of pure water has been taken), $R$ is the universal gas constant, $M_{\mathrm{w}}$ is the molar mass of water, $T$ is the absolute temperature, $\rho_{\mathrm{w}}$ is the density of water and $\kappa$ is the hygroscopicity parameter, which depends on particle composition. The critical supersaturation ( $\mathrm{SS}_{\text {crit }}$ ) of a particle with a certain size ( $\left.D_{\text {dry }}\right)$ and composition $(\kappa)$ is obtained by numerically searching for the maximum of Eq. (1) as a function of the droplet diameter $(D)$. The hygroscopicity parameter $\kappa$, corresponding to a pair of $D_{\text {dry }}$ and $\mathrm{SS}_{\text {crit }}$ is also obtained by numerically solving the $\mathrm{SS}_{\text {crit }}-D_{\mathrm{dry}}-\kappa$-relationship for $\kappa$.

The critical supersaturation increases with decreasing dry diameter due to the Kelvin effect (exponential term in Eq. 1). Consequently, a certain supersaturation determines an activation threshold dry diameter $\left(D_{\text {act }}\right)$ above which all particles of the same or greater hygroscopicity act as $\mathrm{CCN}$.

\subsection{Retrieving the effective peak supersaturation of a cloud}

In the presence of a cloud, the activation threshold diameter $\left(D_{\text {act }}\right)$ can be experimentally determined from the measured interstitial and total number size distributions. Combining $D_{\text {act }}$ with the aerosol hygroscopicity, obtained from the simultaneous CCNC measurements, allows the inference of the effective peak supersaturation of the cloud $\left(\mathrm{SS}_{\text {peak }}\right)$ using the $\kappa$-Köhler theory from Sect. 3.2. The full sequence of calculations required to infer $\mathrm{SS}_{\text {peak }}$ is described below, and illustrated in Fig. 2.

Step 1: the ambient activated fraction size distribution $\left(\operatorname{AF}\left(D_{\text {dry }}\right)\right)$, defined as the fraction of the particles with dry diameter $D_{\text {dry }}$ that have been activated to form cloud droplets, is calculated from the simultaneously measured total and interstitial particle number size distributions $n_{\text {tot }}\left(D_{\text {dry }}\right)$ and $n_{\text {int }}\left(D_{\text {dry }}\right)$ :

$\operatorname{AF}\left(D_{\text {dry }}\right)=\frac{n_{\text {tot }}\left(D_{\text {dry }}\right)-n_{\text {int }}\left(D_{\text {dry }}\right)}{n_{\text {tot }}\left(D_{\text {dry }}\right)}=\frac{n_{\text {cr }}\left(D_{\text {dry }}\right)}{n_{\text {tot }}\left(D_{\text {dry }}\right)}$

The difference of $n_{\text {tot }}\left(D_{\text {dry }}\right)$ minus $n_{\text {int }}\left(D_{\text {dry }}\right)$ corresponds to the number size distribution of cloud residuals $\left(n_{\mathrm{cr}}\left(D_{\text {dry }}\right)\right)$, i.e. of particles that have been activated to cloud droplets.

A typical example of an activation curve observed during a liquid cloud event is shown in Fig. 3b. Small particles remain interstitial, while with increasing diameter the activated fraction approaches a value of approximately 1 (if no entrainment occurs after particle activation in the vicinity of the JFJ and no ice particles are present). It can also be seen that the activation curve as a function of dry diameter in an ambient 


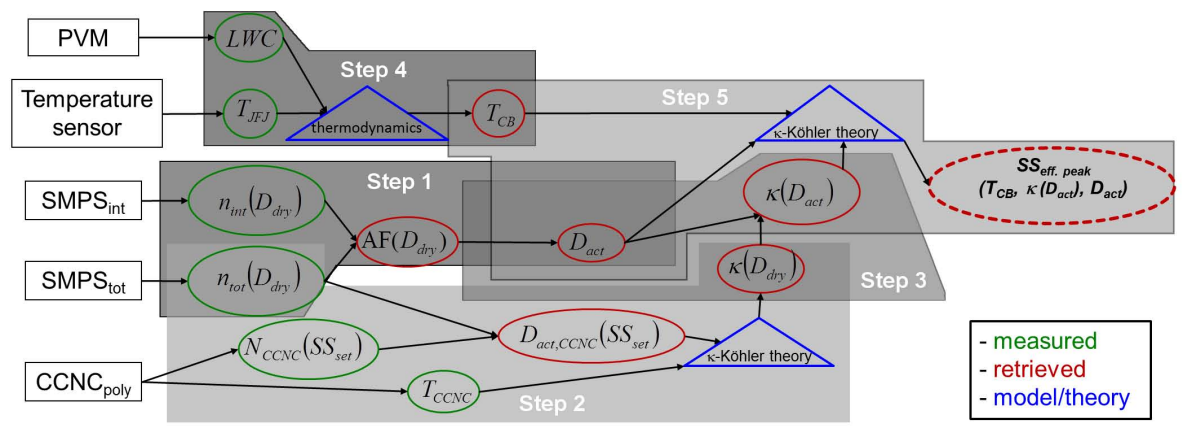

Fig. 2. Procedure illustrating how the effective peak supersaturation is retrieved. In rectangles the instruments used are depicted, in circles the measured and calculated parameters are shown and the triangles represent theoretical calculations. The "thermodynamic" triangle is the theory explained in Sect. 3.3, Step 4. LWC is the liquid water content, $T_{\mathrm{JFJ}}$ is the temperature measured at the JFJ, $T_{\mathrm{CB}}$ is the temperature at the cloud base, $n_{\text {int }}\left(D_{\text {dry }}\right)$ is the interstitial aerosol size distribution, $n_{\text {tot }}\left(D_{\text {dry }}\right)$ is the total aerosol size distribution and $N_{\mathrm{CCNC}}\left(\mathrm{SS}_{\mathrm{set}}\right)$ is the number concentration of CCNs per SS. $\mathrm{AF}\left(D_{\text {dry }}\right)$ is the activated fraction as a function of dry diameter retrieved from the SMPS measurements. $D_{\text {act }}$ is the activation diameter estimated from the SMPS measurements and $D_{\text {act,CCNC }}\left(\mathrm{SS}_{\text {set }}\right)$ is the ambient activation diameter estimated from the combining of the SMPS and CCNC measurements per SS at the temperature of activation in the CCNC. $\kappa\left(D_{\text {dry }}\right)$ is the hygroscopicity parameter as function of the particle diameter estimated from the CCNC measurements and $\kappa\left(D_{\text {act }}\right)$ is the hygroscopicity parameter estimated for the ambient conditions at the ambient activation diameter.

cloud is a smooth transition from approximately 0 to approximately 1 across a range of diameters rather than a sharp step function. This can be attributed to the variability of the chemical composition of individual particles and of the effective peak supersaturation that they experienced on their way to the JFJ (see detailed discussion in Sect. 4.3). The diameter at which $50 \%$ of the particles of this size were activated is defined as the dry activation diameter $\left(D_{\text {act }}\right)$ of the observed cloud (i.e. $D_{\text {act }}$ fulfills $\operatorname{AF}\left(D_{\text {act }}\right)=0.5$ ).

Step 2: in this step the hygroscopicity parameter is determined as a function of particle size using the $\mathrm{CCN}$ number concentration and the total particle number size distribution measured with the CCNC and SMPS, respectively. First, an effective dry activation diameter $\left(D_{\text {act,CCNC }}\right)$ can be obtained for each SS set in the CCNC ( $\left.\mathrm{SS}_{\mathrm{set}}\right)$ assuming a sharp activation cut-off leading to the following implicit equation (Jurányi et al., 2011):

$N_{\mathrm{CCN}}\left(\mathrm{SS}_{\mathrm{set}}\right)=-\int_{D_{\max }}^{D_{\text {act, CCNC }}\left(\mathrm{SS}_{\mathrm{set}}\right)} n_{\mathrm{tot}}(D) \mathrm{d} \log D$

The total number size distribution is integrated from its upper end $\left(D_{\max }\right)$ down to the diameter at which the measured $\mathrm{CCN}$ number concentration $\left(N_{\mathrm{CCN}}\left(\mathrm{SS}_{\text {set }}\right)\right)$ is matched (see Fig. 3c). This diameter is then defined as $D_{\text {act, }, C C N C}\left(\mathrm{SS}_{\text {set }}\right)$.

Equation (1) shows that the relationship between supersaturation and activation diameter depends on temperature. Thus, it is not possible to directly relate the ambient $D_{\text {act }}$ to the $D_{\text {act,CCNC }}-\mathrm{SS}_{\text {set }}$-relationship inferred from the CCNC measurements, as the activation in the CCNC occurs at a temperature of $T_{\mathrm{CCNC}} \approx 298 \mathrm{~K}$, whereas the cloud droplets are formed at the temperature of the cloud base $\left(T_{\mathrm{CB}}\right)$, which was in the range $T_{\mathrm{CB}} \approx 265-278 \mathrm{~K}$ during CLACE2011.

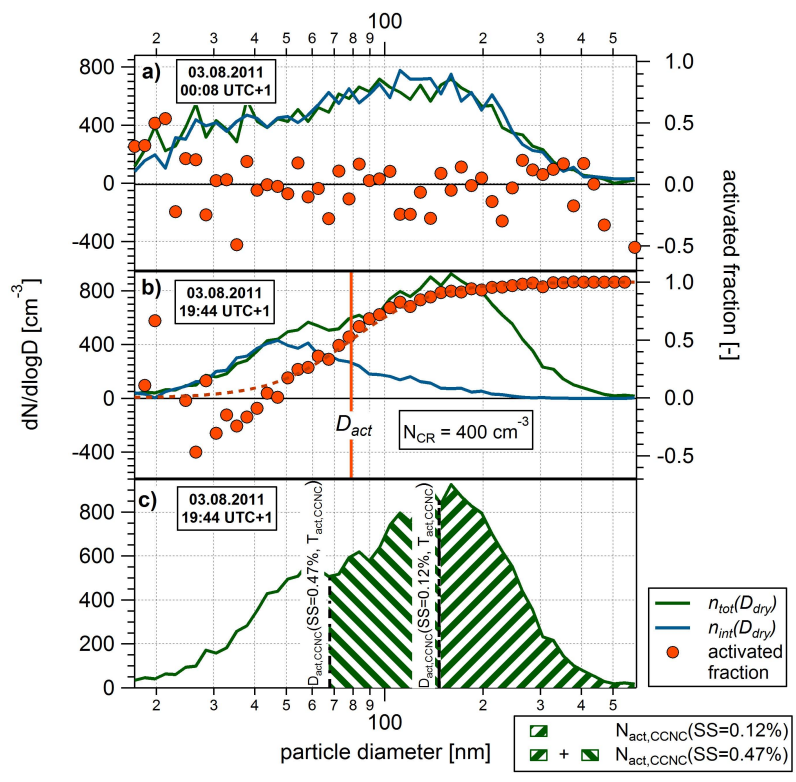

Fig. 3. Hourly averaged aerosol number size distributions measured behind the total and interstitial inlet for an out-of-cloud event (a) and a cloud event (b). The right axis in (a) shows the calculated activated fraction for the cloud event. The median shows the activation diameter where $50 \%$ of the particles acted as $\operatorname{CCN}\left(D_{\text {act }}\right)$. The dashed line is a hill equation fit used to derive $D_{\text {act }} . N_{\mathrm{CR}}$ is the number of cloud residuals that correspond to the number of CCNs that were activated to cloud droplets at ambient conditions. In (c) a particle size distribution is shown with integrating from its upper end until the integrated area is equal to the number of $\mathrm{CCN}$ measured in the CCNC. This results in the activation diameter corresponding to the set $\mathrm{SS}$ in the CCNC $\left(D_{\text {act, CCNC }}\left(\mathrm{SS}_{\text {set }}\right)\right)$. 


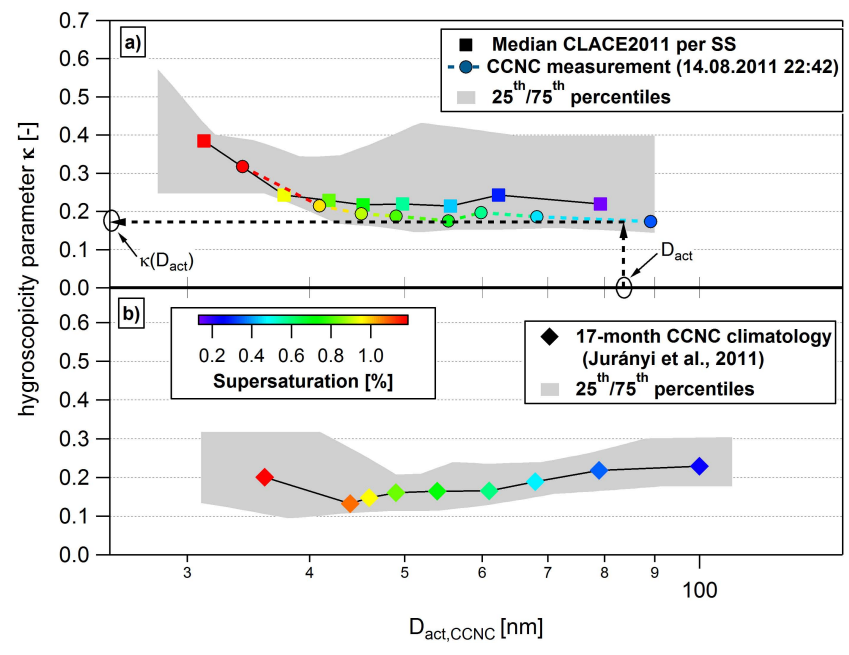

Fig. 4. Example of calculated critical dry diameter $\left(D_{\text {act,CCNC }}\right)$ and hygroscopicity parameter $(\kappa)$ from the averaged CCNC measurements during CLACE2011 and a single, randomly picked example $\mathrm{CCN}$ spectrum measured by the CCNC at 8 different supersaturations on 14 August 2011 between 21:54 and 22:42 (a). The 25th and 75 th percentiles are indicated. In (b) the 17-month climatology of CCNC measurements is shown from Jurányi et al. (2011). The $D_{\text {act,CCNC }}$ has been calculated by integrating the particle number size distribution (measured behind the total inlet) from its upper end down to $D_{\text {act }}$. The diameter at which the integrated number concentration equals the measured $\mathrm{CCN}$ number concentration at the certain supersaturation (SS), corresponds to $D_{\text {act,CCNC }}\left(\mathrm{SS}_{\mathrm{set}}\right)$ (see hatched area from Fig. 3c). The dashed arrows show how the $\kappa$ value can be retrieved for a particular $D_{\text {act }}$.

We can account for this temperature dependence by using the hygroscopicity parameter $(\kappa)$, which is assumed to be only dependent on the chemical composition of the particle and not on the temperature. The hygroscopicity parameter of the ambient aerosol as a function of particle size, $\kappa\left(D_{\text {dry }}\right)$, is obtained, with a time-resolution of approximately $1 \mathrm{~h}$, from the measured $D_{\text {act,CCNC }}-\mathrm{SS}_{\text {set }}$-pairs and the corresponding activation temperature $\left(T_{\mathrm{CCNC}}\right.$, which is close to the temperature measured at the entry of the CCNC's activation column) using the $\kappa$-Köhler theory described in Sect. 3.2. This step provides the data shown in Fig. 4a and discussed in Sect. 4.2.

Step 3: the hygroscopicity of the particles at the activation threshold diameter in the ambient cloud, $\kappa\left(D_{\text {act }}\right)$, is retrieved by linear interpolation of the $\kappa(D)$-curve, obtained from Step 2, to the diameter $D_{\text {act }}$. The interpolation of Step 3 is illustrated with the dashed black arrows in Fig. 4a for the example data from 14 August 2011, 22:42 LT.

Step 4: the cloud base temperature $\left(T_{\mathrm{CB}}\right)$, at which the cloud droplet activation predominately occurs, is inferred from the liquid water content (LWC) of the cloud observed at the Jungfraujoch. First, the total water content (TWC), expressed as a partial pressure of water ( $\left.p_{\mathrm{TWC}, \mathrm{JFJ}}\right)$ corresponding to the same amount of water if it was all in the gas phase, is calculated as:

$p_{\mathrm{TWC}, \mathrm{JFJ}}=p_{\mathrm{LWC}, \mathrm{JFJ}}+p_{\mathrm{Sat}}\left(T_{\mathrm{JFJ}}\right)$,

where $p_{\mathrm{LWC}, \mathrm{JFJ}}$ (calculated via the ideal gas law) is the partial pressure of water corresponding to the LWC measured by the PVM at the JFJ, $T_{\mathrm{JFJ}}$ is the ambient temperature at the $\mathrm{JFJ}$, and $p_{\text {sat }}(T)$ is the saturation vapour pressure of water as a function of temperature (Goff and Gratch, 1946). The cloud base can then be found in an iterative approach with reducing the altitude, $h$, in fixed steps of $\Delta h=0.17 \mathrm{~m}$ :

$h_{i+1}=h_{i}-\Delta h$

The temperature of the next altitude layer is obtained from the previous value under the assumption of a constant wet adiabatic lapse rate of $\Lambda_{\text {wet }}=0.006 \mathrm{Km}^{-1}$ (Wallace and Hobbs, 2006):

$T_{i+1}=T_{i}-\Lambda_{\text {wet }} \Delta h$

This corresponds to a temperature difference of $\approx-0.001 \mathrm{~K}$ per layer.

The change of atmospheric pressure with changing altitude results in a proportional change of the total water content per volume of air, which can be calculated with the barometric height formula:

$p_{\mathrm{TWC}, i+1}=p_{\mathrm{TWC}, i}\left(1-\frac{M_{\mathrm{air}} g}{R T_{i}} \Delta h\right)$,

where $M_{\text {air }}$ is the mean molar mass of air $\left(0.02896 \mathrm{~kg} \mathrm{~mol}^{-1}\right), g$ is the gravitational acceleration and $R$ the ideal gas constant. Equation (7) includes the assumption that the total water content is preserved, i.e. that water removal due to precipitation is negligible. The iteration over the altitude layers is started with the conditions at the Jungfraujoch, i.e. $h_{0}=h_{\mathrm{JFJ}}, T_{0}=T_{\mathrm{JFJ}}, p_{\mathrm{TWC}, 0}=p_{\mathrm{TWC}, \mathrm{JFJ}}$. The iteration is stopped at the cloud base, which is at the index $j$, where the water partial pressure (assuming all water is in the gas phase) is equal to the saturation vapour pressure over liquid water:

$p_{\mathrm{TWC}, j}=p_{\mathrm{sat}}\left(T_{j}\right)$

The altitude $\left(h_{\mathrm{CB}}\right)$ and temperature $\left(T_{\mathrm{CB}}\right)$ at cloud base temperature are then obtained as $h_{j}$ and $T_{j}$, respectively.

Step 5: the activation threshold diameter ( $D_{\text {act }}$; step 1), the hygroscopicity of these particles $\left(\kappa\left(D_{\text {act }}\right)\right.$; Steps 2 and 3$)$ and the temperature at the point of activation $\left(T_{\mathrm{CB}}\right.$ at cloud base; Step 4) are now available. The theoretical critical supersaturation corresponding to these values, which we define as the effective peak supersaturation $\left(\mathrm{SS}_{\text {peak }}\right)$ of the cloud, is then obtained with the $\kappa$-Köhler theory described in Sect. 3.2.

The above input parameters required for retrieving the $\mathrm{SS}_{\text {peak }}$ values are tainted with experimental uncertainty, which is estimated to be $\pm 10 \%$ and $\pm 15 \%$ for $D_{\text {act }}$ and 
the LWC, respectively. The LWC uncertainty propagates into an uncertainty of around $\pm 0.2 \mathrm{~K}$ for $T_{\mathrm{CB}}$, when applying Step 4 . The variability ( $25 \mathrm{th} / 75$ th percentiles) of the $\kappa-D_{\mathrm{dry}}{ }^{-}$ relationship from the 17-month climatology of CCNC measurements (Jurányi et al., 2011, shading in Fig. 4b) is used as an estimate for the uncertainty of $\kappa\left(D_{\text {act }}\right)$. Propagating these uncertainties of the input parameters for Step 5 provides a relative uncertainty of around $\pm 30 \%$ for the $\mathrm{SS}_{\text {peak }}$ values. Uncertainties based on the assumptions made in the five steps for retrieving $\mathrm{SS}_{\text {peak }}$ are not accounted for in the $\pm 30 \%$ experimental uncertainty. However, these assumptions should not have a big influence on the overall uncertainty of $\mathrm{SS}_{\text {peak }}$.

\subsection{Estimation of the updraft velocity at the cloud base}

An important parameter defining $\mathrm{SS}_{\text {peak }}$ is the updraft velocity at the point of aerosol activation (Reutter et al., 2009). It has to be expected that the updraft velocity measured at the JFJ $\left(w_{\mathrm{JFJ}}\right)$ differs from that at the place where cloud formation occurred. Thus, an estimate of the updraft velocity at cloud base $\left(w_{\text {act }}\right)$ was calculated from the horizontal wind speed measured at the JFJ research station, making the following assumptions about the wind field around the JFJ (see also Fig. 5): (1) the air approaching the JFJ research station strictly followed the terrain, i.e. the flow lines are parallel to the surface (at least in the lowest layers). (2) Neither sideways convergence nor divergence of the flow lines occurred between cloud base and the JFJ. Thus, the horizontal wind speed component stays the same between cloud base and the JFJ. With these assumptions, $w_{\text {act }}$ is obtained from the horizontal wind speed measured at the Jungfraujoch $\left(v_{\mathrm{h}, \mathrm{JFJ}}\right)$ :

$w_{\mathrm{act}}=\tan (\alpha) v_{\mathrm{h}, \mathrm{JFJ}}$,

where $\alpha$ denotes the inclination angle of the flow lines at cloud base. The true updraft velocity at cloud base would be smaller than $w_{\text {act }}$ calculated with Eq. (9) if the flow lines would not strictly follow the terrain (i.e. if condition 1 from above was not fulfilled). Thus the calculated $w_{\text {act }}$ can be considered to be a plausible estimate for an upper limit of the true updraft velocity at cloud base.

According to the topography software "Atlas der Schweiz 3.0" from Swisstopo and ETH Zurich, the terrain has a mean inclination of $\alpha \approx 46^{\circ}$ and $\alpha \approx 15^{\circ}$ over the last $700 \mathrm{~m}$ altitude difference before reaching the JFJ for northerly and southerly advection, respectively (see Fig. 5), which is close to the estimated location of the median cloud base during CLACE2011. As explained in Sect. 2.2, $v_{\mathrm{h}, \mathrm{JFJ}}$ was measured with the Rosemount anemometer.

\section{Results and discussions}

\subsection{Meteorological conditions during CLACE2011}

The weather conditions at the JFJ during CLACE2011 can be divided into two different periods: July 2011 was the coldest

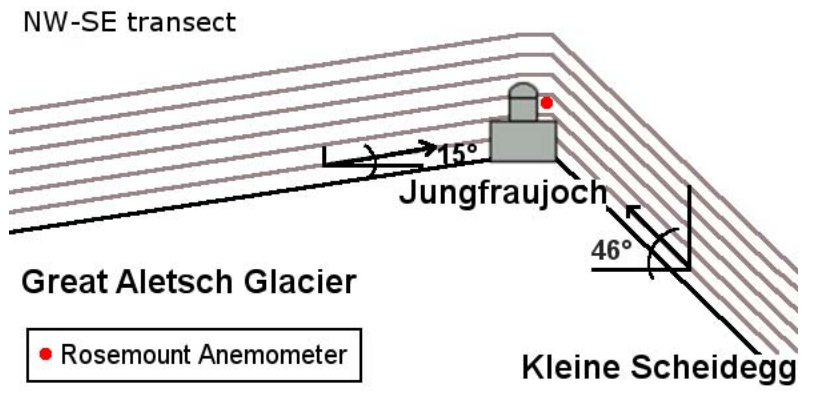

Fig. 5. Influence of the topography on the vertical wind field around the Jungfraujoch. Air masses are assumed to follow the terrain, i.e. the flow lines are assumed to be parallel to the surface in the lowest layers. The mean inclination angles at the mean cloud base positions are $\approx 15^{\circ}$ and $\approx 46^{\circ}$ at the southeastern and northwestern side, respectively.

July since 2000 and cloudier than normal, while August 2011 was one of the five warmest months in Switzerland since 1864 and sunnier compared to the average of 1961-1990 (MeteoSchweiz, 2012). At the end of June and beginning of July, dry polar air was dominant in northern Switzerland and the central Alps. This was associated with sunny but cold weather and with temperatures being especially low during the night. After 7 July, southwesterly winds brought humid air to the Alpine region. Clouds formed more frequently at the JFJ and often thunderstorms, as well as heavy rainfall with hail developed over large areas of Switzerland. After a ridge of high pressure from 14 to 16 July that brought some sunny weather, a persistent supply of dry polar air towards the Alps was present. Therefore, colder temperatures and rather rainy weather was present during the second half of July. In the last week of July, northerly Foehn winds (warm dry air descending in the lee of a mountain range; Brinkmann, 1971) dominated the weather in southern Switzerland. Hence, the JFJ was frequently within clouds. Applying the cloud period criterion defined in Sect. 3.1 to the data of CLACE2011, an in-cloud occurrence of $93.7 \mathrm{~h}$ was found (out of $424.5 \mathrm{~h}$ of valid measurements, corresponding to $22 \%$ ).

By the beginning of August, humid air was brought to Switzerland due to a low pressure system over western Europe which resulted in frequent showers and occasional intense rainfalls. From mid-August until the end of the campaign (24 August 2011) a persistent high pressure system was dominating the weather in Switzerland with a high number of sunny hours and high temperatures.

Figure 6 gives an overview of the most important meteorological parameters and the cloud presence during CLACE2011. In Fig. 6a, the temperature $\left(T_{\mathrm{JFJ}}\right)$ is shown together with the LWC. The value of $T_{\mathrm{JFJ}}$ varies during the campaign, with a minimum value of $-12.3^{\circ} \mathrm{C}$ and a maximum value of $11.6^{\circ} \mathrm{C}$. Figure $6 \mathrm{~b}$ depicts the local wind direction and horizontal speed. During CLACE2011, the wind 


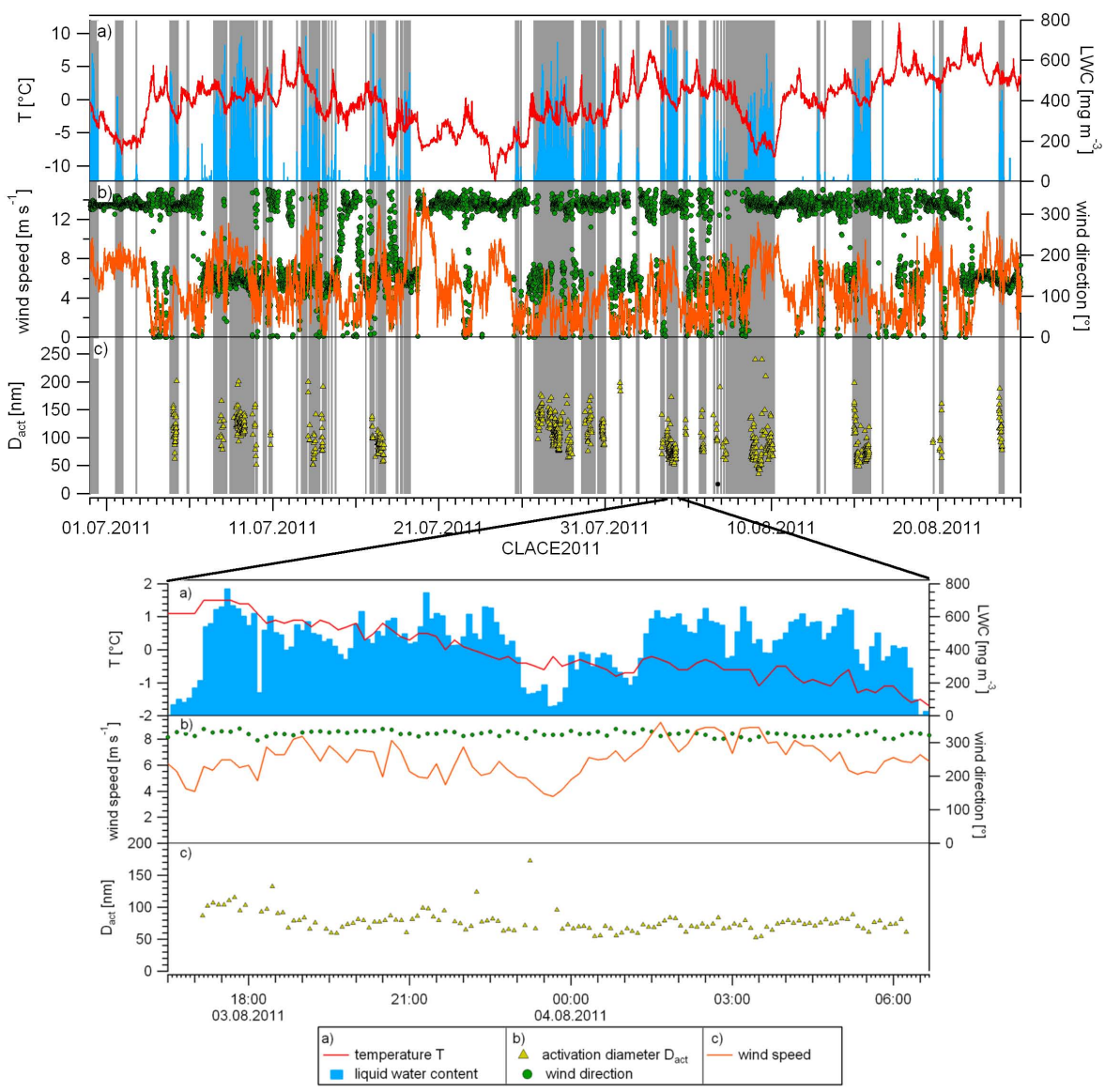

Fig. 6. Measured meteorological parameters during CLACE2011: (a) temperature ( $T$ ) and relative humidity (RH) (b) measured wind direction and horizontal wind speed (c) ambient activation diameter $D_{\text {act }}$. In grey the classified cloud periods during CLACE2011 are depicted by applying the cloud period criterion explained in Sect. 3.1. Below is a zoomed-in case example for the cloud period from 3 August 2011 16:30 to 4 August 2011 06:40.

came from the southeastern sector $40 \%$ of the time and from the northwestern sector $60 \%$ of the time. The horizontal wind speed varied from $0.01 \mathrm{~m} \mathrm{~s}^{-1}$ up to $16 \mathrm{~m} \mathrm{~s}^{-1}$. In Fig. 6c, the $D_{\text {act }}$ values of the observed clouds are shown (see detailed discussion in Sect. 4.3). These values ranged between $35 \mathrm{~nm}$ and $240 \mathrm{~nm}$; at the beginning of cloud periods $D_{\text {act }}$ usually had a larger value than after cloud development. As can be seen in the case example of Fig. 6 the $D_{\text {act }}$ values stayed fairly constant as soon as the cloud had developed.

\subsection{CCNC-derived particle hygroscopicity}

The particle hygroscopicity parameter $\kappa$ is required as a function of particle size for the approach applied in this study to infer the effective peak supersaturation of the clouds which were observed (see Sect. 3.2, step 3). $\kappa\left(D_{\text {dry }}\right)$ was determined from $\mathrm{CCN}$ and particle number size distribution measurements as described in Sect. 3.3, step 2. For the CLACE 2011 campaign, $\kappa\left(D_{\text {dry }}\right)$ was obtained from simultaneous time-resolved $\mathrm{CCN}$ and total aerosol size distribution measurements. While total aerosol size distributions are available for all campaigns, no simultaneous $\mathrm{CCN}$ measurements were available for the other CLACE summer campaigns. Therefore, averaged data of $\kappa\left(D_{\text {dry }}\right)$ from a 17-month climatology of CCN properties measured at the JFJ between May 2008 and September 2009 (Jurányi et al., 2011) were used for those campaigns.

Figure 4 shows the median $\kappa$ values that were measured during CLACE2011 (Fig. 4a) as well as those from the 17month climatology of Jurányi et al. (2011) (Fig. 4b). For the time-resolved CCN data measured during CLACE2011 (see Fig. $4 \mathrm{a}$ ), the $\kappa$ values are centered around 0.22 except for slightly larger $\kappa$ values observed at the smallest covered particle diameter of $31.2 \mathrm{~nm}$ (highest $\mathrm{SS} ; \mathrm{SS}=1.06 \%$ ). Jurányi et al. (2011) reported an overall median $\kappa$ of 0.2 (see Fig. 4b). The $\kappa$ values from the two datasets agree with each other and fall within the previously observed and modelled range of values for continental aerosols of $\kappa \approx 0.1-0.4$ (e.g. Pringle et al., 2010; Andreae and Rosenfeld, 2008).

The variability in the 17 -month climatology of $\kappa$ values for the individual SS remains fairly low in time (shown as 
a shading for the 25th and 75th percentiles of all data during the 17 months in Fig. 4b). This limited variability and the fact that the retrieved effective peak supersaturation values are only moderately sensitive to the $\kappa$ values (see Sect. 4.3 for details), make it possible to use the CCN climatology data, when simultaneous CCN measurements are not available, without introducing much additional uncertainty $(<2 \%)$ in the retrieved effective peak supersaturations.

\subsection{Observed activation diameters and effective peak supersaturations}

The dry activation threshold diameter $\left(D_{\text {act }}\right)$ was inferred from the total and interstitial particle number size distribution measurements during liquid cloud events as described in Step 1 of the data analysis procedure (Sect. 3.3, Fig. 2). The statistics of the observed $D_{\text {act }}$ values is provided in Table 2 for all 5 CLACE summer campaigns included in this study. The median $D_{\text {act }}$ averaged over all campaigns, which can be considered to be representative for liquid cloud activation at the JFJ during the summer season, is $87 \mathrm{~nm}$. This is in close agreement with the observations at the Jungfraujoch during CLACE 2000 previously reported by Henning et al. (2002). The conditions during cloud formation in the vicinity of the JFJ were characterised by considerable variability. The observed $D_{\text {act }}$ values range between 49 and $195 \mathrm{~nm}$ (10th and 90th percentiles), which overlaps with the range of typical $D_{\text {act }}$ values in liquid clouds reported in other studies (e.g. Lihavainen et al., 2008; Asmi et al., 2012; Anttila et al., 2012).

The $D_{\text {act }}$ values observed at the Jungfraujoch, combined with particle hygroscopicity data from $\mathrm{CCN}$ measurements and cloud properties (LWC), form the basis to infer the effective peak supersaturation, $\mathrm{SS}_{\text {peak }}$, of the clouds according to the methodology detailed in Sect. 3.3 and Fig. 2. The CCN activation behaviour of the particles, required in Step 3 of the data analysis procedure, was taken from the averaged CCN climatology data for the JFJ available in the literature (Jurányi et al., 2011). For the CLACE2011 campaign, the $\mathrm{SS}_{\text {peak }}$ values were additionally inferred using data from concurrent time-resolved CCN measurements (see Sect. 4.2). The two alternative sets of SS $_{\text {peak values inferred for the CLACE2011 }}$ campaign with the two alternative sets of $\mathrm{CCN}$ data showed excellent agreement between each other, with the orthogonal regression yielding a slope of 0.99 , an intercept of -0.002 and an $R^{2}$ of 0.99 (see also Fig. 7). This confirms that it is possible to use the averaged CCN climatology data for retrieving the $\mathrm{SS}_{\text {peak }}$ values as it was done for the other campaigns.

Statistics of the $\mathrm{SS}_{\text {peak }}$ values are presented in Table 2 for each CLACE summer campaign separately and as a grand average. The median $\mathrm{SS}_{\text {peak }}$ is on average $0.35 \%$. However, the $\mathrm{SS}_{\text {peak }}$ values exhibit large variability with typical values of $\sim 0.12 \%$ and $0.75 \%$ for the 10th and 90th percentiles, respectively. The local topography imposes two distinct wind sectors (Sect. 2.1, Fig. 1): NW $\left(225^{\circ}\right.$ to $\left.45^{\circ}\right)$ and SW $\left(45^{\circ}\right.$ to

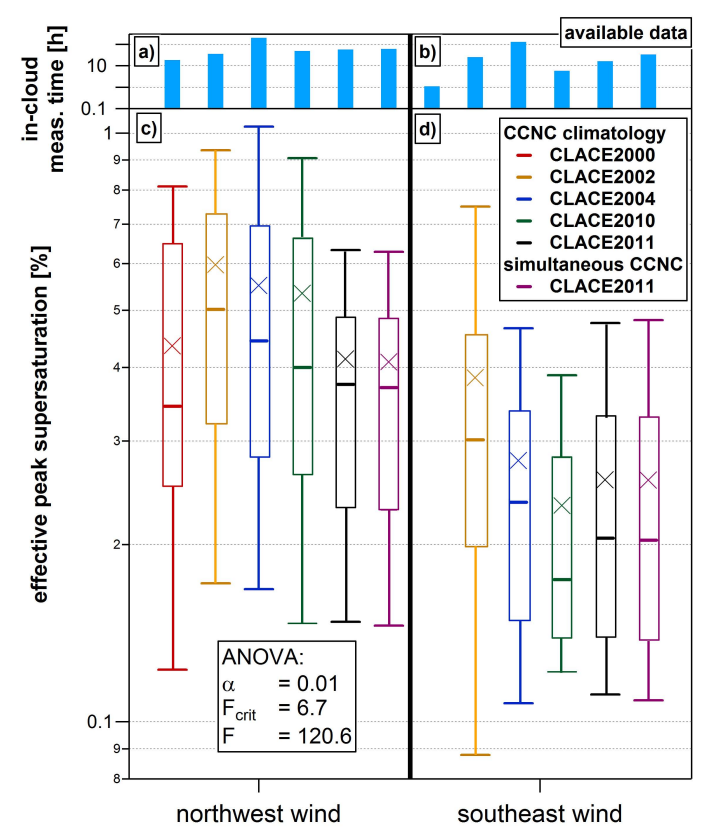

Fig. 7. In-cloud measurement time during the CLACE campaigns for (a) northwestern wind (local wind direction is between $225^{\circ}$ to $\left.45^{\circ}\right)$ and (b) southeastern wind $\left(225^{\circ}\right.$ to $\left.45^{\circ}\right)$. 10th, 25th, 50th (median), 75th, and 90th percentiles (boxplot) and mean value (cross) of the effective peak supersaturation $\left(\mathrm{SS}_{\text {peak }}\right)$ for (c) northwestern and (d) southeastern wind. The $F$ value of the ANOVA is much larger than the critical $F$ value for $\alpha=0.01$, which indicates a significant difference between the mean $\mathrm{SS}_{\text {peak }}$ for all data under northwestern and southeastern wind conditions. For CLACE2011 SS has additionally been retrieved with using the concurrent CCNC measurements (purple) alternatively to using the climatology data (black). The statistics for southeastern wind during CLACE2000 is not shown because only $1.1 \mathrm{~h}$ of valid in-cloud data is available.

$225^{\circ}$ ). Figure 7 reveals a systematic difference in the $\mathrm{SS}_{\text {peak }}$ values between these two wind sectors (all data between $225^{\circ}$ to $45^{\circ}$ are included in the NW sector and all data from $45^{\circ}$ to $225^{\circ}$ in the SE sector). For conditions where the local wind was blowing from the northwestern sector, the $\mathrm{SS}_{\text {peak }}$ ranged from $0.23 \%$ to $0.73 \%$ (25th and 75 th percentiles of the data from all CLACE campaigns) with a median value of $0.41 \%$, while for conditions where the wind was blowing from the southeastern sector, $\mathrm{SS}_{\text {peak }}$ ranged from $0.14 \%$ to $0.45 \%$ with a median value of $0.22 \%$. To test the significance of differences between the $\mathrm{SS}_{\text {peak }}$ values for the two wind sectors, a univariate analysis of variance (ANOVA) was performed. This standard statistical tool tests, based on the variance of different considered data groups, if their means are significantly different from each other at a specified level of significance. The two datasets of $\mathrm{SS}_{\text {peak }}$ values (i.e. NW and SW wind conditions) were analysed with the ANOVA tool implemented in the IGOR Pro software (Wavemetrics Inc.), in which the $F$ value is computed to test the null hypothesis (Brown and Forsythe, 1974). For an acceptable null 
Table 2. Statistical values of the effective peak supersaturation $\left(\mathrm{SS}_{\text {peak }}\right)$ and activation diameter $\left(D_{\text {act }}\right)$ during all CLACE summer campaigns (for CLACE2000 only NW wind conditions). Simultaneous CCN data used for CLACE2011 and CCN climatology data used for CLACE2000, 2002, 2004 and 2010.

\begin{tabular}{|c|c|c|c|c|c|c|c|c|c|c|c|c|}
\hline & \multicolumn{2}{|c|}{ CLACE2000 } & \multicolumn{2}{|c|}{ CLACE2002 } & \multicolumn{2}{|c|}{ CLACE2004 } & \multicolumn{2}{|c|}{ CLACE2010 } & \multicolumn{2}{|c|}{ CLACE2011 } & \multicolumn{2}{|c|}{ All campaigns } \\
\hline & $\mathrm{SS}_{\text {peak }}[\%]$ & $D_{\text {act }}[\mathrm{nm}]$ & $\mathrm{SS}_{\text {peak }}[\%]$ & $D_{\text {act }}[\mathrm{nm}]$ & $\mathrm{SS}_{\text {peak }}[\%]$ & $D_{\text {act }}[\mathrm{nm}]$ & $\mathrm{SS}_{\text {peak }}[\%]$ & $D_{\text {act }}[\mathrm{nm}]$ & $\mathrm{SS}_{\text {peak }}[\%]$ & $D_{\text {act }}[\mathrm{nm}]$ & $\mathrm{SS}_{\text {peak }}[\%]$ & $D_{\text {act }}[\mathrm{nm}]$ \\
\hline 10th/90th percentile & 0.12 & 164 & 0.12 & 134 & 0.12 & 154 & 0.11 & 138 & 0.12 & 139 & 0.12 & 146 \\
\hline 25 th $/ 75$ th percentile & 0.25 & 113 & 0.21 & 107 & 0.20 & 117 & 0.21 & 108 & 0.19 & 120 & 0.21 & 113 \\
\hline median & 0.34 & 91 & 0.40 & 78 & 0.33 & 88 & 0.35 & 83 & 0.33 & 96 & 0.35 & 87 \\
\hline 75 th/25th percentile & 0.65 & 63 & 0.66 & 60 & 0.67 & 65 & 0.60 & 63 & 0.47 & 75 & 0.61 & 65 \\
\hline 90th/10th percentile & 0.81 & 56 & 0.88 & 49 & 0.84 & 51 & 0.87 & 51 & 0.60 & 63 & 0.80 & 54 \\
\hline mean & 0.43 & 100 & 0.51 & 97 & 0.44 & 100 & 0.49 & 92 & 0.38 & 101 & 0.45 & 98 \\
\hline
\end{tabular}

hypothesis the $F$ values $(F)$ would be close to 1 and would indicate that the mean $\mathrm{SS}_{\text {peak }}$ values were approximately equal independent of the wind direction. The ANOVA also computes a critical $F$ value $\left(F_{\text {crit }}\right)$ above which $F$ must lie to show a significant difference within the denoted probability level $\alpha$ (Stahel, 2007). The ANOVA results are presented in Fig. 7. The difference of the mean $\mathrm{SS}_{\text {peak }}$ values between the northwestern and southeastern wind sectors is significant on a $\alpha=0.01$ probability level $\left(F=120.6, F_{\text {crit }}=6.7\right)$. The reasons for this difference will be discussed in Sect. 4.4.

In Table 3, the $\mathrm{SS}_{\text {peak }}$ values calculated in this study are compared to values calculated from measurements or modelled in other studies. Here, it can be seen that the retrieved $\mathrm{SS}_{\text {peak }}$ values from the JFJ are within the range of values reported in the literature. More specifically, the $\mathrm{SS}_{\text {peak values }}$ observed for the northwestern wind conditions (overall median $\mathrm{SS}_{\text {peak }}=0.41 \%$ ) correspond to the range of values typically reported for cumulus clouds (Mason, 1971; Pruppacher and Klett, 2007). Clouds from the southeast have an overall median $\mathrm{SS}_{\text {peak }}$ of $0.22 \%$, which matches literature values of shallow layer clouds (Ghan et al., 1998; Zhang et al., 2004; Pruppacher and Klett, 2007). This corresponds with visual observations at the JFJ: clouds approaching the JFJ from the south typically appear as shallow layer clouds while clouds approaching from the NW usually have the appearance of cumulus clouds.

\subsection{Parameters influencing the effective peak supersaturation}

In this section, we evaluate the possible reasons for the observed significant difference between the $\mathrm{SS}_{\text {peak }}$ values for northwestern and southeastern wind conditions which has been reported in the previous section. Generally, the $\mathrm{SS}_{\text {peak }}$ depends on the updraft velocity (cooling rate acts as source term) and the number concentration of CCN (cloud droplets act as sink term). For a given supersaturation, the number concentration of $\mathrm{CCN}$ depends on the aerosol number size distribution and particle hygroscopicity. A high value of $\mathrm{SS}_{\text {peak }}$ can be caused by a high updraft velocity or few CCN (i.e. few sufficiently large particles and/or low particle hygroscopicity). Conversely, a low value of $\mathrm{SS}_{\text {peak }}$ can be caused by small updraft velocity or many CCN (i.e. many large parti- cles and/or high particle hygroscopicity). Directly investigating the influence of these parameters on $\mathrm{SS}_{\text {peak }}$ through correlation analyses is difficult due to the noise of the $6 \mathrm{~min}$ data and the limited time resolution of the hygroscopicity data. Instead we investigate by means of the analyses presented in Fig. 8, for the CLACE 2011 dataset, if the significant difference between the $\mathrm{SS}_{\text {peak }}$ values observed under $\mathrm{NW}$ and SE wind conditions can be attributed to differences in these parameters for the two wind directions. An ANOVA was performed for all parameters presented in Fig. 8 to test whether their mean values are significantly different between NW and SE wind conditions (significant differences, i.e. $F>F_{\text {crit }}$, are indicated by a "*" behind the $F$ value). Figure 8 a recapitulates the results for the effective peak supersaturation for comparison with the other parameters.

Unfortunately, no direct measurement of the updraft velocity at cloud base is available. Therefore, two proxies for the updraft at cloud base are shown in Fig. 8b. The parameter $w_{\mathrm{JFJ}}$ is the updraft velocity measured at the JFJ by the ultrasonic anemometer (Sect. 2.2), and $w_{\text {act }}$ is the estimated updraft velocity at cloud base (inferred from the horizontal wind speed at the JFJ, as measured by the Rosemount pitot tube anemometer, with using Eq. (9); see Sect. 3.4). The $w_{\text {act }}$ values are higher than the $w_{\mathrm{JFJ}}$ values. A correlation analysis including all data shows that they exhibit a moderate linear correlation (slope $=0.76, y$ intercept $=-0.43 \mathrm{~m} \mathrm{~s}^{-1}$ and $\left.R^{2}=0.33\right)$. Neither parameter is expected to accurately represent the true updraft at cloud base. The wind field around the JFJ is likely to be very complex due to the surrounding topography. The measurement location is situated atop a rocky pinnacle in a pass between two mountain peaks. Air approaching from the north or the south is therefore funneled from relatively wide valleys through the narrow pass. Additionally, low level air approaching along the Lauterbrunnen valley to the north will be forced to rise along the steep rocky northern slope, which includes numerous bluffs, ridges and other complex terrain features. Direct measurements of vertical wind velocities at the cloud base in such an area are extremely difficult to perform, and have therefore not been attempted. Thus it is not possible to determine the true updraft velocity at the cloud base. However, simplifying the topography in the vicinity of the JFJ with only two slopes (to the NW and SE of JFJ) is a possibility for retrieving a qualitative 
Table 3. Different effective peak supersaturations $\left(\mathrm{SS}_{\text {peak }}\right)$; or maximum supersaturation for several cloud types and locations.

\begin{tabular}{llcl}
\hline Cloud type & location & $\mathrm{SS}_{\text {peak }}[\%]$ & Reference \\
\hline cumulus & Jungfraujoch & $0.37-0.5$ & this study \\
shallow layer & Jungfraujoch & $0.17-0.30$ & this study \\
cumulus & continental & $0.25-0.7$ & Pruppacher and Klett (1997) \\
cumulus & maritime & $0.3-0.8$ & Mason (1971) \\
shallow layer & & $\sim 0.05$ & Pruppacher and Klett (1997) \\
shallow layer & modelled (sulfate particles) & $0.05-0.6$ & Ghan et al. (1998) \\
shallow layer & modelled (1-dimensional) & $0.1-0.2$ & Zhang et al. (2004) \\
fog & Po Valley, Italy/modeled & $<0.05$ & Ming and Russell (2004) \\
low-level clouds & Pallas station & $0.2-0.7$ & Anttila et al. (2012) \\
unknown & Puy-de-Dôme & $0.1-0.7$ & Asmi et al. (2012) \\
unknown & eastern Pacific ocean & $\sim 0.3$ & Roberts et al. (2006) \\
low-level stratus & Gulf of Maine/Bay of Fundy & $<0.1$ & Leaitch et al. (1996) \\
\hline
\end{tabular}

updraft velocity as a best estimate for the true updraft velocity present at the cloud base. Nevertheless, the ANOVA indicates, for both parameters $w_{\mathrm{JFJ}}$ and $w_{\text {act }}$, a significant difference with higher updraft for northwestern compared to southeastern wind conditions. Such a difference in updraft velocity is in accordance with the local topography (Figs. 1 and 3). While the local wind is blowing from the northwestern sector, the air is forced to rise up along the steep slope of the mountain face. While the wind is blowing from southeastern sector the air is slowly rising over the less steep slope of the Aletsch glacier. Overall, this gives clear evidence that the difference of updraft velocity at cloud base contributes to the observed difference in $\mathrm{SS}_{\text {peak }}$ between the two distinct wind sectors.

The $w_{\text {act }}$ values for NW wind cases are between 1.3 and $6.2 \mathrm{~m} \mathrm{~s}^{-1}$ with a median value of $4 \mathrm{~ms}^{-1}$. This range of updraft velocities falls within the typical range for cumulusclouds (1 to $10 \mathrm{~ms}^{-1}$ ) as described in Houze (1994). The $w_{\text {act }}$ values for southeast wind cases are between 0.63 and $2.8 \mathrm{~m} \mathrm{~s}^{-1}$ with a median value of $1.9 \mathrm{~ms}^{-1}$. This median value of updraft velocities is slightly higher than the one given for shallow-layer clouds $\left(0.8 \mathrm{~m} \mathrm{~s}^{-1}\right)$ described in Vogelmann et al. (2012), while the range of updraft values agree quite well between the two studies. Thus, the estimated updraft velocities $\left(w_{\text {act }}\right)$ are also consistent with visual observations at the JFJ, indicating mostly cumulus and shallow layer clouds for northwestern and southeastern wind conditions, respectively.

Figure $8 \mathrm{c}$ shows the distribution of $\kappa$ values for two example SS of $0.14 \%$ and $0.34 \%$. According to the ANOVA, the difference between mean $\kappa$ values under NW and SE wind conditions is not significant at $\mathrm{SS}=0.14 \%$, while the difference is just about significant for the mean $\kappa$ values at $\mathrm{SS}=0.34 \%$. However, this difference at $\mathrm{SS}=0.34 \%$ is influenced by few very high $\kappa$ values under SE wind conditions, while the median $\kappa$ value actually shows a trend in opposite direction. A very weak dependence of particle hygroscopicity at the JFJ on wind direction is consistent with find- ings from previous long-term observations at this site (Kammermann et al., 2009; Juranyi et al., 2011). Thus, we conclude that the potential difference in hygroscopicity of the particles approaching the JFJ from the southeastern or northwestern sectors is not large enough to explain the observed differences in $\mathrm{SS}_{\text {peak }}$.

The number concentration of particles $\left(N_{96-600}\right)$ with dry diameters between 96 and $600 \mathrm{~nm}$ is calculated by integrating the particle number size distribution measured behind the total inlet. The lower integration boundary of $96 \mathrm{~nm}$ was chosen to match the median $D_{\text {act }}$ of all cloud events during CLACE2011, such that $N_{96-600}$ represents the CCN number concentration at the median cloud formation conditions. A larger $N_{96-600}$ (larger number concentration of $\mathrm{CCN}$ ) would result in a larger cloud droplet number concentration and thus in a lower $\mathrm{SS}_{\text {peak }}$, due to the increased condensation sink term, compared to a cloud formed at equal updraft velocity and equal LWC but with a smaller $N_{96-600}$ (smaller number concentration of $\mathrm{CCN}$ ). The box plots presented in Fig. 8d reveal that $N_{96-600}$ is $\sim 1.5-2.0$ times larger for southeastern compared to northwestern wind conditions. Figure 8e shows that the difference in potential $\mathrm{CCN}$ results in slightly larger droplet residual particle number concentration $\left(N_{\text {cr }}\right.$; calculated from the total and interstitial particle number size distributions as described in Sect. 3.3). This confirms that the larger number concentration of potential $\mathrm{CCN}$ under southeastern wind conditions indeed results in a larger cloud droplet number condensation and thus in a larger condensation sink term compared to NW wind conditions. Consequently, the difference in $N_{96-600}$ also contributes to the observed difference in $\mathrm{SS}_{\text {peak }}$ between SE and NW wind conditions.

Summarising, the results presented in Fig. 8 show that systematic differences of the mean updraft velocity and the mean CCN number concentration between NW and SE wind cases result in a systematic difference of the mean $\mathrm{SS}_{\text {peak }}$ in clouds formed in the vicinity of the JFJ. The relative importance of these two parameters cannot be quantified with 

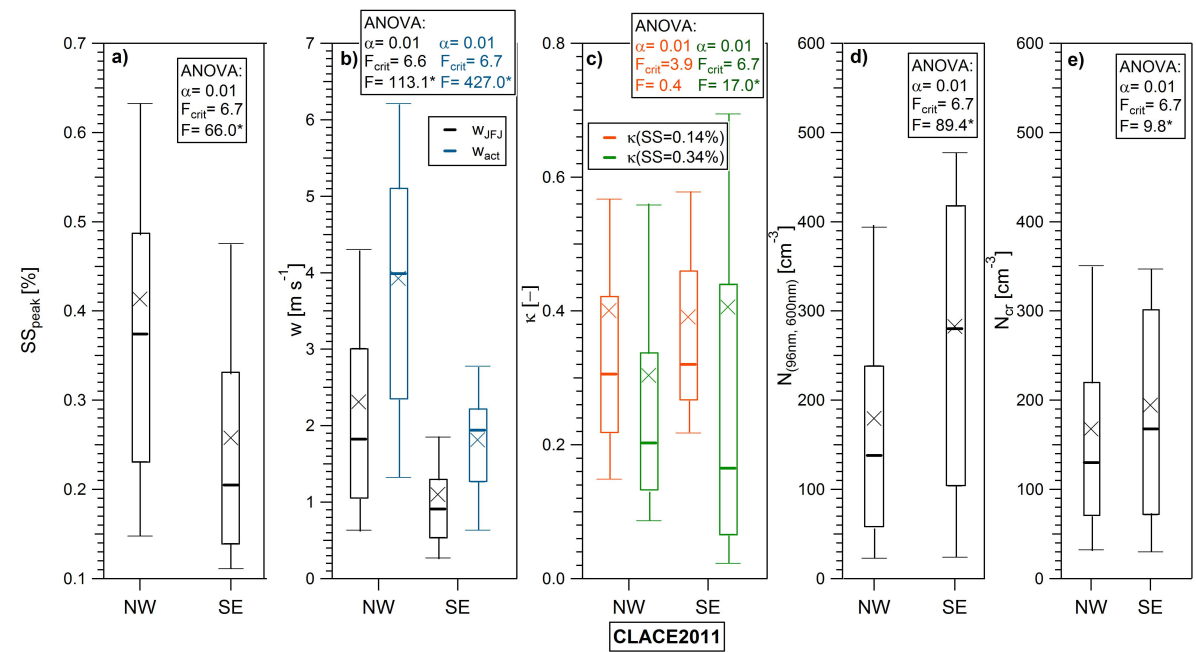

Fig. 8. Dependence of various parameters on wind direction for cloud periods (LWC 30th percentile $>5 \mathrm{mg} \mathrm{m}^{-3}$ ) during CLACE2011: (a) the effective peak supersaturation. (b) Updraft velocity measured at the Jungfraujoch and the retrieved updraft velocity at the point of activation. (c) Hygroscopicity parameter (retrieved from the CCNC measurements for two example SS). (d) The cloud droplet residual particle number concentration. (e) The number concentration of particles in the size range of $96 \mathrm{~nm}$ (median $D_{\text {act }}$ of CLACE2011) to 600 nm (upper limit of the SMPS). The 10th, 25th, 50th (median), 75th and 90th percentiles and mean value (x) of each parameter are shown. A " $*$ " behind the $F$ values denotes that the ANOVA indicates a significant difference between the mean values of a parameter for northwestern and southeastern wind conditions.

the experimental results. However, the box model simulations presented in the next section show that the difference in updraft velocity has the dominant influence, while the difference of the CCN number concentration only has a minor effect.

\subsection{Modelling the effective peak supersaturation and potential turbulence effects}

\subsubsection{Observational data}

In our analysis, the updraft velocity is based on 6 min averages of wind data. In reality, turbulence is often present in clouds on a shorter time scale.

In Fig. 9, the relationship between $\mathrm{SS}_{\text {peak }}$ and $w_{\text {act }}$ is shown, for all CLACE2011 NW wind cases (panel a) and $\mathrm{SE}$ wind cases (panel b). Additionally, the standard deviation of $w_{\mathrm{JFJ}}\left(\sigma_{\mathrm{wJFJ}}\right)$ was calculated from wind observations at the JFJ ( $20 \mathrm{~Hz}$ time resolution), indicated by the colour coding of the points in Fig. 9. It is readily apparent, in Fig. 9, that there is a rather weak correlation between $w_{\text {act }}$ and $\mathrm{SS}_{\text {peak }}$. For both NW and SE wind cases, as $w_{\text {act }}$ increases, so too do the maximum observed values of $\mathrm{SS}_{\text {peak }}$. However, particularly in the NW wind case, the spread between the maximum and minimum $\mathrm{SS}_{\text {peak }}$ for a particular $w_{\text {act }}$ also increases with increasing $w_{\text {act }}$.

The most likely explanation for this behaviour is that the wind velocity fluctuates, and at higher mean wind velocities, the possible range over which the velocity can fluctuate is larger. Due to the influence of $w_{\text {act }}$ on $\mathrm{SS}_{\text {peak }}$, larger fluctu- ations in $w_{\text {act }}$ (i.e. larger $\sigma_{\mathrm{wJFJ}}$ ) will result in a larger spread of values of $\mathrm{SS}_{\text {peak }}$.

\subsubsection{Box modelling results}

In addition to the measured data, the Zurich optical and microphysical model (ZOMM) was used in this study to simulate the effective peak supersaturation experienced by an air parcel during cloud droplet activation for the typical cloud formation conditions around the JFJ. ZOMM is a box model which calculates the evolution of an initial aerosol distribution along a temperature and pressure trajectory. A detailed description of ZOMM can be found in Luo et al. (2003) and Hoyle et al. (2005). In order to simulate the $\mathrm{SS}_{\text {peak }}$ as a function of updraft velocity for CLACE2011, ZOMM was initialised with median values of the altitude, temperature and pressure at cloud base and of the dry aerosol number size distribution. Medians of these quantities were separately calculated for southeasterly and for northwesterly wind conditions from the values observed at the JFJ during CLACE2011, in order to obtain representative cloud simulations for the two wind sectors. The differences in temperature and pressure at cloud base between NW and SE had only negligible influence on the modelled updraft vs. $\mathrm{SS}_{\text {peak }}$ relationship, whereas the difference in $\mathrm{CCN}$ number concentration had a detectable influence. Particle hygroscopicity was described with using median $\kappa$ values of 0.22 for the NE wind case and 0.26 for the SE wind case. The model was initialised below cloud base at water vapour sub-saturated conditions, and run along linear trajectories with a constant updraft velocity. 

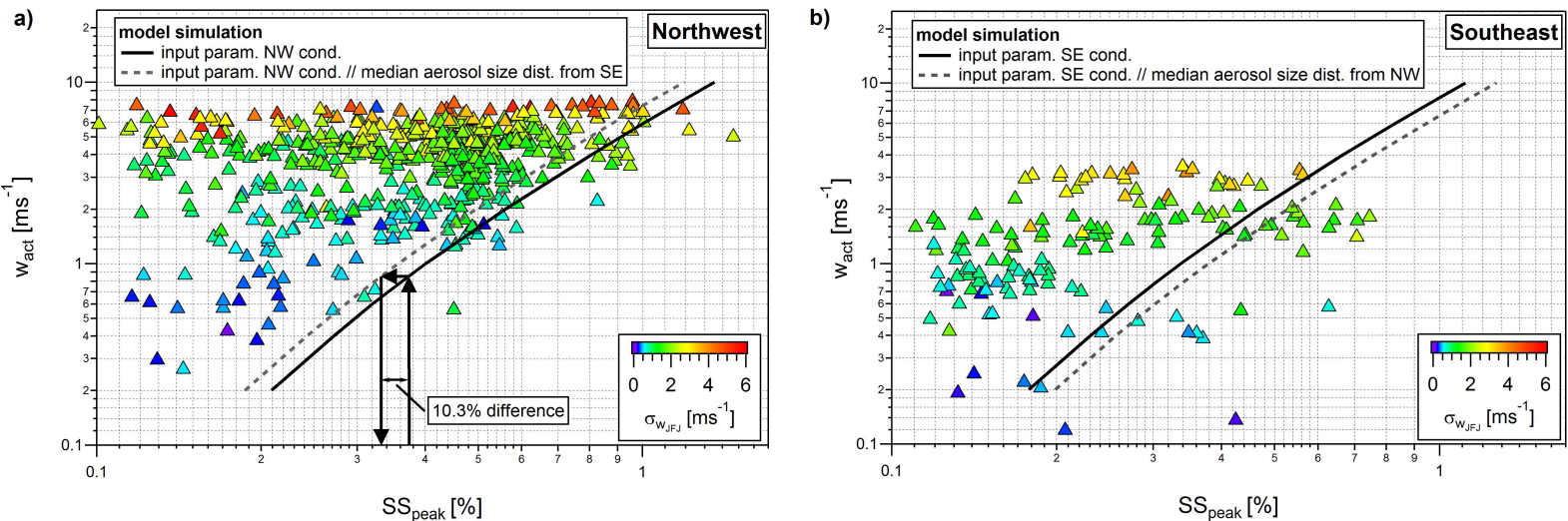

Fig. 9. 6 min averages of the retrieved updraft velocity at point of aerosol activation ( $w_{\text {act }}$ ) (see text for further explanation) as a function of the effective peak supersaturation $\left(\mathrm{SS}_{\text {peak }}\right)$. The points are colour coded to show the standard deviation of the updraft velocity measured at the JFJ $\left(\sigma_{\mathrm{wJFJ}}\right)$. Panel (a) shows results for the northwest wind case, panel (b) shows results for the southeast wind case. The black line indicates the model simulations with mean input parameters for each wind direction for CLACE2011. The grey dotted line indicates the model simulations with median input parameters for each wind direction for CLACE2011 but with swapped aerosol size distribution as input parameter.

As the air parcel cools, a full kinetic calculation of the water uptake by the aerosols is performed. The highest SS reached along the trajectory is recorded, and these values represent the modelled effective peak supersaturation. The black curves in Fig. 9a and b, representing the box model simulations of $\mathrm{SS}_{\text {peak }}$, were obtained by running the simulation for a range of updraft velocities with using the respective boundary conditions for the northwesterly and southeasterly wind conditions.

An important result of the model simulation is the fact that the two model curves for $\mathrm{SS}_{\text {peak }}$ as a function of $w_{\text {act }}$ differ only little between the northwestern and southeastern cases (the average difference is $11.4 \%$; for the median $\mathrm{SS}_{\text {peak }}$ for CLACE2011 the difference is $10.3 \%$ ), while the observed $\mathrm{SS}_{\text {peak }}$ differed on average by as much as a factor of 1.8 . As the differences between the model runs for northwestern and southeastern winds in temperature and pressure at cloud base have only negligible influence, the main difference was the number of aerosol particles (which were taken to be the median of the distributions observed from each wind direction). This shows that the mean difference in potential CCN can only have a minor influence on the systematic difference between the mean observed $\mathrm{SS}_{\text {peak }}$ for the two wind cases. Opposed to this, changing the updraft velocity in the model be a factor of two, which corresponds to the factor between the mean observed updraft velocities for the two wind cases, reduces the resulting $\mathrm{SS}_{\text {peak }}$ by about $34 \%$ (when starting from the mean NW case). Thus, it is very likely that the difference in the mean observed $\mathrm{SS}_{\text {peak }}$ between NW and SE cases is for the most part caused by different updraft velocity, while systematic differences in the CCN number concentration only have a minor influence. The difference in updraft velocity is likely, at least to some extent, driven by the differ- ent topography, though we cannot directly prove this nor can we exclude some influence from differences in the meteorological conditions.

Particularly for the northwestern wind cases, the model generally overestimates the $\mathrm{SS}_{\text {peak }}$ for a particular $w_{\text {act }}$. The exact reasons for this difference will be investigated in a subsequent study. However, here it can be speculated about three possible causes: firstly, the estimated $w_{\text {act }}$, calculated from the horizontal wind speed at the JFJ with using Eq. (9), may overestimate the true updraft at cloud base due to flow convergence in the approach to the narrow gap in which the JFJ is located, or due to flow lines that do not strictly follow the terrain (entrainment of dry air can be excluded based on the cloud event filtering discussed in Sect. 3.1). Indeed, reducing $w_{\text {act }}$ for the observation based points by a factor of 5 would lead to a near perfect agreement with the modelled data. Secondly, an initially heterogeneous mixed air mass before cloud activation would lower the $\mathrm{SS}_{\text {peak }}$ and thus lead to an underestimation of $\mathrm{SS}_{\text {peak }}$ for a particular $w_{\text {act }}$. Thirdly, turbulence is neglected in the simulation. However, considering turbulence in the model is expected to increase the $\mathrm{SS}_{\text {peak }}$ for a particular $w_{\text {act }}$, which would increase the difference between observations and model results even further. Thus, neglecting turbulence cannot be the sole reason for this difference.

\section{Conclusions}

CCN number concentrations at ten different SS were measured together with aerosol size distributions behind a total and interstitial inlet at the high-altitude research station Jungfraujoch in Switzerland.

The hygroscopicity parameter $\kappa$ was calculated for the data collected during CLACE2011, and values for the range 
of particle diameters were found to be centred around 0.2, falling within the previously observed and modelled range of values for continental aerosols of $\kappa \approx 0.1-0.4$ (e.g. Pringle et al., 2010; Andreae and Rosenfeld, 2008).

A new method was presented to accurately derive the prevailing effective peak supersaturation within the observed cloud. For earlier measurement campaigns, where no $\mathrm{CCN}$ number concentrations were measured, a 17-month CCN climatology was used to estimate the effective peak supersaturation for these campaigns as well. The statistical data analysis was performed for the two main wind directions at the JFJ.

The analysis shows that the clouds coming from the SE experienced distinctly smaller overall median effective peak supersaturations with less variation (median $\mathrm{SS}_{\text {peak }}=0.22 \%$; 25 th percentile $=0.14 \%$ and 75 th percentile $=0.33 \%$ ) compared to clouds reaching the Jungfraujoch from the NW (median $\mathrm{SS}_{\text {peak }}=0.41 \% ; 25$ th percentile $=0.25 \%$ and 75 th percentile $=0.63 \%$ ). The difference in the median particle hygroscopicity cannot explain these differences as the $\kappa$ values are fairly constant and do not depend on the wind direction. The number concentration of potential $\mathrm{CCN}$ at equal SS (acting as condensation sink term for $\mathrm{SS}_{\text {peak }}$ ) differed substantially between the NW and SE wind cases. However, the box model simulation showed that the difference of the mean $\mathrm{CCN}$ number concentration only had a minor influence on the difference between the observed $\mathrm{SS}_{\text {peak }}$ values.

It is hypothesized that the local topography determines the cloud formation to a large extent: the north side of the Jungfraujoch is quite steep and thus forces the air masses to rise with a higher updraft velocity resulting in higher supersaturations.

To test this hypothesis, the horizontal wind speed measured at the Jungfraujoch was used to estimate the updraft velocity at the point of aerosol activation, based on the estimated air mass streamlines around the Jungfraujoch rock. The observed factor of 2 difference in median updraft velocity between NW and SE conditions can explain the difference of the median $\mathrm{SS}_{\text {peak }}$ for the most part according to the model simulations. These values were correlated with the derived effective peak supersaturation. Although a general trend of increasing effective peak supersaturation with increasing updraft velocity was found, there is a large amount of scatter in the data, especially towards higher updraft velocities.

A set of input parameters, representative of the ambient air and aerosol properties at the JFJ during CLACE2011, were used to show the theoretical relationship between effective peak supersaturation and updraft velocity. For both NW and SE wind cases, the model generally overestimates the effective peak supersaturation at a given updraft velocity; possibly, because the qualitative estimate of the updraft velocity at cloud base inferred from the wind measurements at the Jungfraujoch potentially overestimates the true updraft velocity at cloud base. The increasing spread in observed $\mathrm{SS}_{\text {peak }}$ with increasing updraft velocity is most likely due to an increase in the variability of the wind velocity at higher wind speeds.

Acknowledgements. This work was supported by MeteoSwiss in the framework of the Global Atmosphere Watch programme, FP7 project ACTRIS (grant agreement no. 262254), as well as the Swiss National Science Foundation (SNSF) (grant number 200021 140663). We thank the International Foundation High Altitude Research Station JFJ and Gornergrat for the opportunity to perform experiments on the Jungfraujoch.

Edited by: L. M. Russell

\section{References}

Albrecht, B. A.: Aerosols, cloud microphysics, and fractional cloudiness, Science, 245, 1227-1230, doi:10.1126/science.245.4923.1227, 1989.

Allan, J. D., Baumgardner, D., Raga, G. B., Mayol-Bracero, O. L., Morales-García, F., García-García, F., Montero-Martínez, G., Borrmann, S., Schneider, J., Mertes, S., Walter, S., Gysel, M., Dusek, U., Frank, G. P., and Krämer, M.: Clouds and aerosols in Puerto Rico - a new evaluation, Atmos. Chem. Phys., 8, 1293 1309, doi:10.5194/acp-8-1293-2008, 2008.

Andreae, M. O. and Rosenfeld, D.: Aerosol-cloudprecipitation interactions. Part 1 . The nature and sources of cloud-active aerosols, Earth-Sci. Rev., 89, 13-41, doi:10.1016/j.earscirev.2008.03.001, 2008.

Anttila, T., Vaattovaara, P., Komppula, M., Hyvärinen, A.-P., Lihavainen, H., Kerminen, V.-M., and Laaksonen, A.: Sizedependent activation of aerosols into cloud droplets at a subarctic background site during the second Pallas Cloud Experiment (2nd $\mathrm{PaCE}$ ): method development and data evaluation, Atmos. Chem. Phys., 9, 4841-4854, doi:10.5194/acp-9-4841-2009, 2009.

Anttila, T., Brus, D., Jaatinen, A., Hyvärinen, A.-P., Kivekäs, N., Romakkaniemi, S., Komppula, M., and Lihavainen, H.: Relationships between particles, cloud condensation nuclei and cloud droplet activation during the third Pallas Cloud Experiment, Atmos. Chem. Phys., 12, 11435-11450, doi:10.5194/acp12-11435-2012, 2012.

Asmi, E., Freney, E., Hervo, M., Picard, D., Rose, C., Colomb, A., and Sellegri, K.: Aerosol cloud activation in summer and winter at puy-de-Dôme high altitude site in France, Atmos. Chem. Phys., 12, 11589-11607, doi:10.5194/acp-12-11589-2012, 2012.

Baltensperger, U., Gaggeler, H. W., Jost, D. T., Lugauer, M., Schwikowski, M., Weingartner, E., and Seibert, P.: Aerosol climatology at the high-alpine site Jungfraujoch, Switzerland, J. Geophys. Res.-Atmos., 102, 19707-19715, doi:10.1029/97jd00928, 1997.

Baltensperger, U., Schwikowski, M., Jost, D. T., Nyeki, S. Gaggeler, H. W., and Poulida, O.: Scavenging of atmospheric constituents in mixed phase clouds at the high-alpine site Jungfraujoch part I: basic concept and aerosol scavenging by clouds, Atmos. Environ., 32, 3975-3983, doi:10.1016/S13522310(98)00051-X, 1998.

Brinkmann, W.: What is a foehn?, Weather, 26, 230-240, 1971. 
Brown, M. B. and Forsythe, A. B.: Anova and multiple comparisons for data with heterogeneous variances, Biometrics, 30, 719-724, doi:10.2307/2529238, 1974.

Collaud Coen, M., Andrews, E., Asmi, A., Baltensperger, U., Bukowiecki, N., Day, D., Fiebig, M., Fjaeraa, A. M., Flentje, H., Hyvärinen, A., Jefferson, A., Jennings, S. G., Kouvarakis, G., Lihavainen, H., Lund Myhre, C., Malm, W. C., Mihapopoulos, N., Molenar, J. V., O’Dowd, C., Ogren, J. A., Schichtel, B. A., Sheridan, P., Virkkula, A., Weingartner, E., Weller, R., and Laj, P.: Aerosol decadal trends - Part 1: In-situ optical measurements at GAW and IMPROVE stations, Atmos. Chem. Phys., 13, 869894, doi:10.5194/acp-13-869-2013, 2013.

Cozic, J., Verheggen, B., Mertes, S., Connolly, P., Bower, K., Petzold, A., Baltensperger, U., and Weingartner, E.: Scavenging of black carbon in mixed phase clouds at the high alpine site Jungfraujoch, Atmos. Chem. Phys., 7, 1797-1807, doi:10.5194/acp-7-1797-2007, 2007.

Cozic, J., Verheggen, B., Weingartner, E., Crosier, J., Bower, K. N., Flynn, M., Coe, H., Henning, S., Steinbacher, M., Henne, S., Collaud Coen, M., Petzold, A., and Baltensperger, U.: Chemical composition of free tropospheric aerosol for $\mathrm{PM}_{1}$ and coarse mode at the high alpine site Jungfraujoch, Atmos. Chem. Phys., 8, 407-423, doi:10.5194/acp-8-407-2008, 2008.

Deng, Z. Z., Zhao, C. S., Ma, N., Ran, L., Zhou, G. Q., Lu, D. R., and Zhou, X. J.: An examination of parameterizations for the $\mathrm{CCN}$ number concentration based on in situ measurements of aerosol activation properties in the North China Plain, Atmos. Chem. Phys., 13, 6227-6237, doi:10.5194/acp-13-6227-2013, 2013.

Ditas, F., Shaw, R. A., Siebert, H., Simmel, M., Wehner, B., and Wiedensohler, A.: Aerosols-cloud microphysicsthermodynamics-turbulence: evaluating supersaturation in a marine stratocumulus cloud, Atmos. Chem. Phys., 12, 2459-2468, doi:10.5194/acp-12-2459-2012, 2012.

Fors, E. O., Swietlicki, E., Svenningsson, B., Kristensson, A., Frank, G. P., and Sporre, M.: Hygroscopic properties of the ambient aerosol in southern Sweden - a two year study, Atmos. Chem. Phys., 11, 8343-8361, doi:10.5194/acp-11-8343-2011, 2011.

Gerber, H.: Supersaturation and droplet spectral evolution in fog, J. Atmos. Sci., 48, 2569-2588, doi:10.1175/15200469(1991)048<2569:Sadsei>2.0.Co;2, 1991.

Ghan, S. J., Guzman, G., and Abdul-Razzak, H.: Competition between sea salt and sulfate particles as cloud condensation nuclei, J. Atmos. Sci., 55, 3340-3347, doi:10.1175/15200469(1998)055<3340:Cbssas>2.0.Co;2, 1998.

Goff, J. A. and Gratch, S.: Low-pressure properties of water from -160 to 212 F, Trans. Amer. Soc. Heat. Vent. Eng., 51, 125-164, 1946.

Henning, S., Weingartner, E., Schmidt, S., Wendisch, M., Gaggeler, H. W., and Baltensperger, U.: Size-dependent aerosol activation at the high-alpine site Jungfraujoch (3580 ma.s.l.), Tellus B, 54, 82-95, doi:10.1034/j.1600-0889.2002.00299.x, 2002.

Houze Jr., R. A.: Cloud Dynamics, vol. 53 of the International Geophysics Series, Academic Press, San Diego, 1994.

Hoyle, C. R., Luo, B. P., and Peter, T.: The origin of high ice crystal number densities in cirrus clouds, J. Atmos. Sci., 62, 2568-2579, doi:10.1175/Jas3487.1, 2005.
IPCC: Climate Change 2007: the Physical Science Basis, Contribution of Working Group I to the Fourth Assessment Report of the Intergovernmental Panel on Climate Change, Cambridge University Press, Cambridge, UK and New York, NY, USA, 2007.

Jurányi, Z., Gysel, M., Weingartner, E., DeCarlo, P. F., Kammermann, L., and Baltensperger, U.: Measured and modelled cloud condensation nuclei number concentration at the high alpine site Jungfraujoch, Atmos. Chem. Phys., 10, 7891-7906, doi:10.5194/acp-10-7891-2010, 2010.

Jurányi, Z., Gysel, M., Weingartner, E., Bukowiecki, N., Kammermann, L., and Baltensperger, U.: A 17 month climatology of the cloud condensation nuclei number concentration at the high alpine site Jungfraujoch, J. Geophys. Res.-Atmos., 116, D10204, doi:10.1029/2010jd015199, 2011.

Kammermann, L., Gysel, A., Weingartner, E., and Baltensperger, U.: Hygroscopicity of tropospheric aerosols: one year of measurements at Jungfraujoch (3580 ma.s.1.), Geochim. Cosmochim. Acta, 73, A618-A618, 2009.

Kammermann, L., Gysel, M., Weingartner, E., and Baltensperger, U.: 13-month climatology of the aerosol hygroscopicity at the free tropospheric site Jungfraujoch (3580 ma.s.1.), Atmos. Chem. Phys., 10, 10717-10732, doi:10.5194/acp-1010717-2010, 2010.

Ketterer, C., Zieger, P., Bukowiecki, N., Collaud Coen, M., Maier, O., Ruffieux, D., and Weingartner, E.: Investigation of the planetary boundary layer in the Swiss Alps using remote sensing and in-situ measurements, Bound.-Lay. Meteorol., 1-18, doi:10.1007/s10546-013-9897-8, 2014.

Kohler, H.: The nucleus in and the growth of hygroscopic droplets, T. Faraday Soc., 32, 1152-1161, doi:10.1039/Tf9363201152, 1936.

Leaitch, W. R., Banic, C. M., Isaac, G. A., Couture, M. D., Liu, P. S. K., Gultepe, I., and Li, S.-M.: Physical and chemical observations in marine stratus during the 1993 North Atlantic Regional Experiment: Factors controlling cloud droplet number concentrations, J. Geophys. Res., 101, 29123-29135, doi:10.1029/96JD01228, 1996.

Lihavainen, H., Kerminen, V.-M., Komppula, M., Hyvärinen, A.P., Laakia, J., Saarikoski, S., Makkonen, U., Kivekäs, N., Hillamo, R., Kulmala, M., and Viisanen, Y.: Measurements of the relation between aerosol properties and microphysics and chemistry of low level liquid water clouds in Northern Finland, Atmos. Chem. Phys., 8, 6925-6938, doi:10.5194/acp-8-6925-2008, 2008.

Luo, B. P., Peter, T., Fueglistaler, S., Wernli, H., Wirth, M., Kiemle, C., Flentje, H., Yushkov, V. A., Khattatov, V., Rudakov, V., Thomas, A., Borrmann, S., Toci, G., Mazzinghi, P., Beuermann, J., Schiller, C., Cairo, F., Di Donfrancesco, G., Adriani, A., Volk, C. M., Strom, J., Noone, K., Mitev, V., MacKenzie, R. A., Carslaw, K. S., Trautmann, T., Santacesaria, V., and Stefanutti, L.: Dehydration potential of ultrathin clouds at the tropical tropopause, Geophys. Res. Lett., 30, 1557, doi:10.1029/2002g1016737, 2003.

Makkonen, L., Lehtonen, P., and Helle, L.: Anemometry in icing conditions, J. Atmos. Ocean. Tech., 18, 1457-1469, doi:10.1175/1520-0426(2001)018<1457:Aiic>2.0.Co;2, 2001.

Mason, B. J.: The Physics of Clouds, Clarendon Press, Oxford, p. $671,1971$.

MeteoSchweiz: Klimabulletin Jahr 2011, Zürich, 2012. 
Ming, Y. and Russell, L. M.: Organic aerosol effects on fog droplet spectra, J. Geophys. Res.-Atmos., 109, D10206, doi:10.1029/2003jd004427, 2004.

Nyeki, S., Li, F., Weingartner, E., Streit, N., Colbeck, I., Gaggeler, H. W., and Baltensperger, U.: The background aerosol size distribution in the free troposphere: an analysis of the annual cycle at a high-alpine site, J. Geophys. Res.-Atmos., 103, 31749-31761, doi:10.1029/1998jd200029, 1998.

Padró, L. T., Moore, R. H., Zhang, X., Rastogi, N., Weber, R. J., and Nenes, A.: Mixing state and compositional effects on CCN activity and droplet growth kinetics of size-resolved $\mathrm{CCN}$ in an urban environment, Atmos. Chem. Phys., 12, 10239-10255, doi:10.5194/acp-12-10239-2012, 2012.

Petters, M. D. and Kreidenweis, S. M.: A single parameter representation of hygroscopic growth and cloud condensation nucleus activity, Atmos. Chem. Phys., 7, 1961-1971, doi:10.5194/acp-71961-2007, 2007.

Pringle, K. J., Tost, H., Pozzer, A., Pöschl, U., and Lelieveld, J.: Global distribution of the effective aerosol hygroscopicity parameter for $\mathrm{CCN}$ activation, Atmos. Chem. Phys., 10, 52415255, doi:10.5194/acp-10-5241-2010, 2010.

Pruppacher, H. R. and Klett, J. D.: Microphysics of clouds and precipitation, Wiley Online Library, Dordrecht, Kluwer Academic Publishers, 2007.

Reutter, P., Su, H., Trentmann, J., Simmel, M., Rose, D., Gunthe, S. S., Wernli, H., Andreae, M. O., and Pöschl, U.: Aerosoland updraft-limited regimes of cloud droplet formation: influence of particle number, size and hygroscopicity on the activation of cloud condensation nuclei (CCN), Atmos. Chem. Phys., 9, 70677080, doi:10.5194/acp-9-7067-2009, 2009.

Roberts, G. C. and Nenes, A.: A continuous-flow streamwise thermal-gradient $\mathrm{CCN}$ chamber for atmospheric measurements, Aerosol Sci. Tech., 39, 206-221, doi:10.1080/027868290913988, 2005.

Roberts, G., Mauger, G., Hadley, O., and Ramanathan, V.: North American and Asian aerosols over the eastern Pacific Ocean and their role in regulating cloud condensation nuclei, J. Geophys. Res.-Atmos., 111, D13205, doi:10.1029/2005jd006661, 2006.

Rose, D., Gunthe, S. S., Mikhailov, E., Frank, G. P., Dusek, U., Andreae, M. O., and Pöschl, U.: Calibration and measurement uncertainties of a continuous-flow cloud condensation nuclei counter (DMT-CCNC): $\mathrm{CCN}$ activation of ammonium sulfate and sodium chloride aerosol particles in theory and experiment, Atmos. Chem. Phys., 8, 1153-1179, doi:10.5194/acp-8-11532008, 2008 .

Seinfeld, J. H. and Pandis, S. N.: Atmospheric Chemistry and Physics - From Air Pollution to Climate Change, 2nd Edn., John Wiley and Sons, Inc., New York, 2006.

Sihto, S.-L., Mikkilä, J., Vanhanen, J., Ehn, M., Liao, L., Lehtipalo, K., Aalto, P. P., Duplissy, J., Petäjä, T., Kerminen, V.M., Boy, M., and Kulmala, M.: Seasonal variation of CCN concentrations and aerosol activation properties in boreal forest, Atmos. Chem. Phys., 11, 13269-13285, doi:10.5194/acp-1113269-2011, 2011
Spiegel, J. K., Zieger, P., Bukowiecki, N., Hammer, E., Weingartner, E., and Eugster, W.: Evaluating the capabilities and uncertainties of droplet measurements for the fog droplet spectrometer (FM-100), Atmos. Meas. Tech., 5, 2237-2260, doi:10.5194/amt5-2237-2012, 2012.

Stahel, W.: Statistische Datenanalyse: Eine Einführung für Naturwissenschaftler, Vieweg + Teubner Verlag, Vieweg, Braunschweig, 2007

Twomey, S. A.: Pollution and cloud albedo, EOS T. Am. Geophys. Un., 58, 797-797, 1977.

Verheggen, B., Cozic, J., Weingartner, E., Bower, K., Mertes, S., Connolly, P., Gallagher, M., Flynn, M., Choularton, T., and Baltensperger, U.: Aerosol partitioning between the interstitial and the condensed phase in mixed-phase clouds, J. Geophys. Res.Atmos., 112, D23202, doi:10.1029/2007jd008714, 2007.

Vogelmann, A. M., McFarquhar, G. M., Ogren, J. A., Turner, D. D., Comstock, J. M., Feingold, G., Long, C. N., Jonsson, H. H., Bucholtz, A., Collins, D. R., Diskin, G. S., Gerber, H., Lawson, R. P., Woods, R. K., Andrews, E., Yang, H. J., Chiu, J. C., Hartsock, D., Hubbe, J. M., Lo, C. M., Marshak, A., Monroe, J. W., McFarlane, S. A., Schmid, B., Tomlinson, J. M., and Toto, T.: Racoro extended-term aircraft observations of boundary layer clouds, B. Am. Meteorol. Soc., 93, 861-878, doi:10.1175/Bams-D-11-00189.1, 2012.

Wallace, J. M. and Hobbs, P. V.: Atmospheric Science: An Introductory Survey, Academic Press, Elsevier, 2006.

Weingartner, E., Nyeki, S., and Baltensperger, U.: Seasonal and diurnal variation of aerosol size distributions $(10<D<750 \mathrm{~nm})$ at a high-alpine site (Jungfraujoch $3580 \mathrm{~m}$ a.s.1.), J. Geophys. Res.-Atmos., 104, 26809-26820, 1999.

Wiedensohler, A., Birmili, W., Nowak, A., Sonntag, A., Weinhold, K., Merkel, M., Wehner, B., Tuch, T., Pfeifer, S., Fiebig, M., Fjäraa, A. M., Asmi, E., Sellegri, K., Depuy, R., Venzac, H., Villani, P., Laj, P., Aalto, P., Ogren, J. A., Swietlicki, E., Williams, P., Roldin, P., Quincey, P., Hüglin, C., FierzSchmidhauser, R., Gysel, M., Weingartner, E., Riccobono, F., Santos, S., Grüning, C., Faloon, K., Beddows, D., Harrison, R., Monahan, C., Jennings, S. G., O'Dowd, C. D., Marinoni, A., Horn, H.-G., Keck, L., Jiang, J., Scheckman, J., McMurry, P. H., Deng, Z., Zhao, C. S., Moerman, M., Henzing, B., de Leeuw, G., Löschau, G., and Bastian, S.: Mobility particle size spectrometers: harmonization of technical standards and data structure to facilitate high quality long-term observations of atmospheric particle number size distributions, Atmos. Meas. Tech., 5, 657-685, doi:10.5194/amt-5-657-2012, 2012.

Zhang, L. M., Michelangeli, D. V., and Taylor, P. A.: Numerical studies of aerosol scavenging by low-level, warm stratiform clouds and precipitation, Atmos. Environ., 38, 4653-4665, doi:10.1016/j.atmosenv.2004.05.042, 2004.

Zhao, C. F., Klein, S. A., Xie, S. C., Liu, X. H., Boyle, J. S., and Zhang, Y. Y.: Aerosol first indirect effects on nonprecipitating low-level liquid cloud properties as simulated by CAM5 at ARM sites, Geophys. Res. Lett., 39, L08806, doi:10.1029/2012g1051213, 2012. 